\title{
A Reconfigurable Triple-Notch-Band Antenna Integrated with Defected Microstrip Structure Band-Stop Filter for Ultra-Wideband Cognitive Radio Applications
}

\author{
Yingsong $L i,{ }^{1}$ Wenxing $L i,{ }^{1}$ and Qiubo $\mathrm{Ye}^{2}$ \\ ${ }^{1}$ College of Information and Communications Engineering, Harbin Engineering University, Harbin, Heilongjiang 150001, China \\ ${ }^{2}$ Communications Research Centre, 3701 Carling Avenue, Ottawa, Canada K2H 8S2 \\ Correspondence should be addressed to Yingsong Li; liyingsong82@gmail.com
}

Received 28 November 2012; Revised 23 May 2013; Accepted 27 May 2013

Academic Editor: Antonio Faraone

Copyright (C) 2013 Yingsong Li et al. This is an open access article distributed under the Creative Commons Attribution License, which permits unrestricted use, distribution, and reproduction in any medium, provided the original work is properly cited.

A printed reconfigurable ultra-wideband (UWB) monopole antenna with triple narrow band-notched characteristics is proposed for cognitive radio applications in this paper. The triple narrow band-notched frequencies are obtained using a defected microstrip structure (DMS) band stop filter (BSF) embedded in the microstrip feed line and an inverted $\pi$-shaped slot etched in the rectangular radiation patch, respectively. Reconfigurable characteristics of the proposed cognitive radio antenna (CRA) are achieved by means of four ideal switches integrated on the DMS-BSF and the inverted $\pi$-shaped slot. The proposed UWB CRA can work at eight modes by controlling switches ON and OFF. Moreover, impedance bandwidth, design procedures, and radiation patterns are presented for analysis and explanation of this antenna. The designed antenna operates over the frequency band between $3.1 \mathrm{GHz}$ and $14 \mathrm{GHz}$ (bandwidth of $127.5 \%$ ), with three notched bands from $4.2 \mathrm{GHz}$ to $6.2 \mathrm{GHz}(38.5 \%), 6.6 \mathrm{GHz}$ to $7.0 \mathrm{GHz}(6 \%$ ), and $12.2 \mathrm{GHz}$ to $14 \mathrm{GHz}(13.7 \%)$. The antenna is successfully simulated, fabricated, and measured. The results show that it has wide impedance bandwidth, multimodes characteristics, stable gain, and omnidirectional radiation patterns.

\section{Introduction}

Recently, the increasing demands for antennas with multiband and multimode operation in modern wireless communication applications have attracted much attention in academia and industry. In particular, UWB systems covering wide bandwidth ranging from $3.1 \mathrm{GHz}$ to $10.6 \mathrm{GHz}$ have been released by Federal Communications Commission (FCC) in 2002 for indoor wireless communications [1]. Since then, the UWB systems have drawn the attention of researchers worldwide because of their low cost, high data rate, and good resistance for multipath and jamming.

A UWB antenna is one of the most important components in the system, and a lot of UWB antennas have been proposed and investigated [2-4], such as microstrip line feed antennas and coplanar waveguide feed antennas. However, the UWB communication systems cover such a wide bandwidth that overlaps with existing narrow band communications applications, such as wireless local area network (WLAN), C-band, X-band, and worldwide interoperability for microwave access (WiMAX). For the sake of reducing the potential interference between UWB systems and narrow band systems, narrow BSFs are added to the end of antennas or equipment to reject the unexpected signals [5], which will certainly increase the cost of the UWB systems. A number of UWB antennas with one or two notched bands have been achieved by using various technologies [5-15], such as slots, stubs, and resonators. Widely used methods are etching various slots on radiation patches and the ground plane, such as C-shaped slots $[6,15]$ and pishaped slots [7]. One effective method is to insert stubs into designed antennas [8]. The inserted stub will generate a notched band without deteriorating radiation patterns. Another effective method is to integrate filters into a UWB antenna which can resist narrow band interference [9]. However, the antennas reported above just work in UWB mode or UWB mode with notched bands, which cannot meet explosive demand on radio spectrum resulted from 


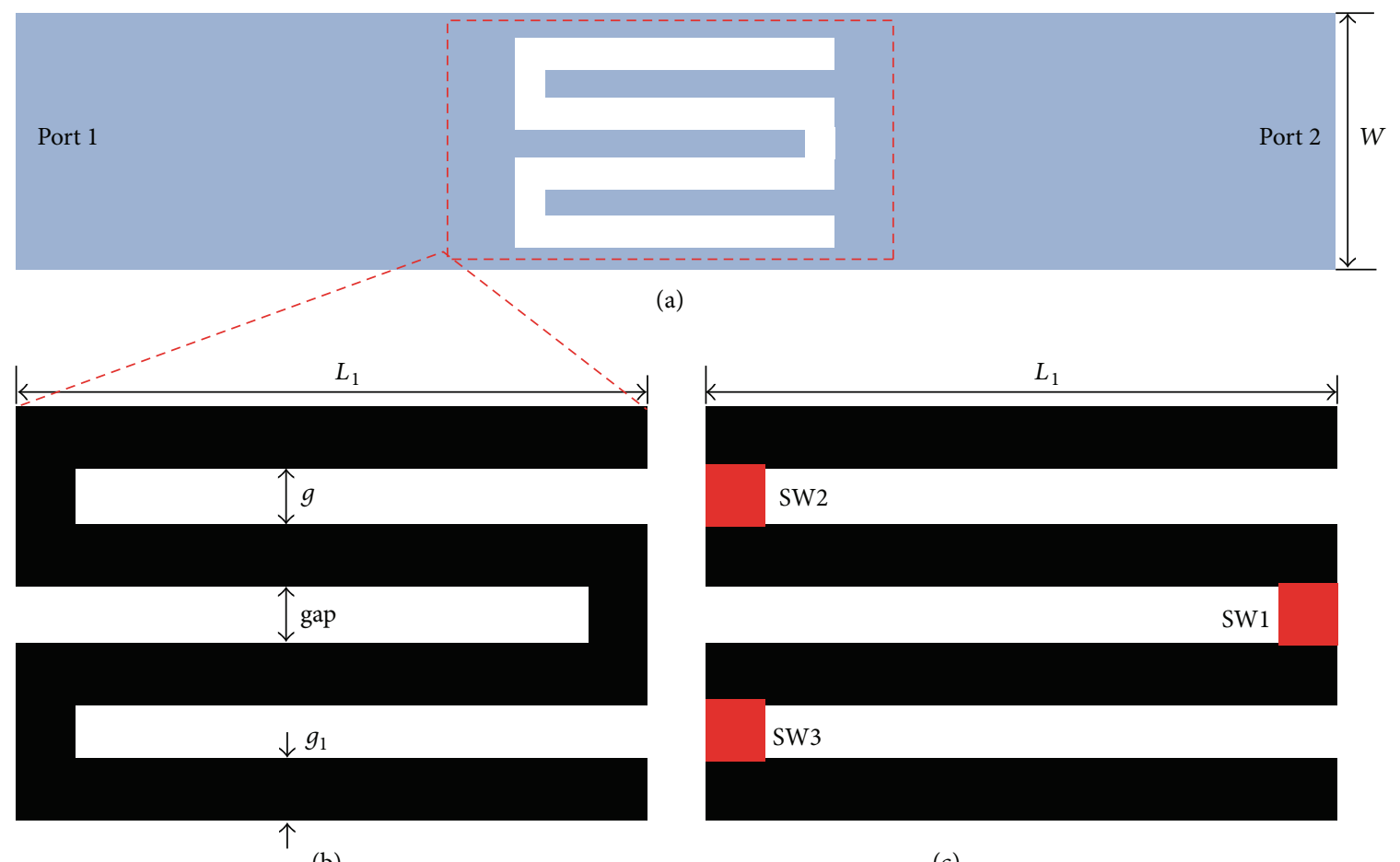

(b)

(c)

Figure 1: Structure of DMS-BSF.

the low cost systems, various communication protocols, and high data rate wireless communication systems [16, 17]. The current spectrum is scarce. In particular, there are many systems working below $10 \mathrm{GHz}$, such as WLAN, C-band, radio frequency identification (RFID), and X-band. Antennas are required to change operating modes to meet multimode wireless communication and cognitive radio applications. A more intelligent method is based on dynamic control, where UWB systems will need an algorithm that can detect the presence of interference from narrow band systems and then avoid it upon detection of its presence. One way to perform dynamic control is based on cognitive radio or software defined radio. In order to meet this requirement, several UWB CRAs with complex single- and dual-port structure have been studied and investigated [16-20]. For single UWB CRAs, the previous design cannot be designed flexibly. Most of the proposed single port CRAs are designed with splitring resonators (SRR) in the radiation patch [19], which will leak electromagnetic wave that deteriorates the radiation patterns.

In this paper, a flexible triple band-notched UWB antenna with reconfigurable characteristics for cognitive radio applications has been studied numerically and experimentally. The triple notched bands are realized using a DMS-BSF embedded in the microstrip feed line and the inverted $\pi$ shaped slot etched on the rectangular radiation patch. The reconfigurable characteristics of cognitive radio applications can be controlled by turning switches at ON state or OFF state. The notched bands can be designed by adjusting the dimensions of DMS-BSF and the inverted $\pi$-shaped slot. The proposed CRA can work on eighth modes which is suitable for multimode, multiband, and UWB cognitive radio communications.

\section{Antenna Design}

In this section, the proposed UWB band-notched antenna integrated with DMS-BSF and the inverted $\pi$-shaped slot for cognitive radio applications is illustrated in detail. Design procedures are divided into four parts. Firstly, we will introduce the DMS-BSF which will be integrated into the UWB CRA. Secondly, the band-notched UWB antenna integrated with the switchable DMS-BSF will be investigated. Thirdly, the band-notched UWB antenna with the inverted $\pi$-shaped slot on the radiation patch will be studied. Finally, we will study the UWB CRA integrated with DMS-BSF and the inverted $\pi$-shaped slot. In this study, the ideal switches for reconfigurability are metal bridges. The presence of the metal bridge represents that the switch status is ON; in contrast, the absence of the metal bridge represents that the switch status is OFF [10, 18, 21, 22]. The simulated results are obtained by using Computer Simulation Technology (CST) Microwave Studio based on finite integration technique (FIT).

2.1. Characteristics of the Proposed DMS-BSF. Currently, there has been a growing interest for research on planar filters using defected ground structures (DGS), photonic band gap (PBG), and electromagnetic band gap (EBG) [23]. Both DGS and $P B G$ have been used for designing and improving the performances of various components, such as filters, antennas, and power amplifiers. However, DGSs etched on ground planes have problems such as radiation from ground plane 

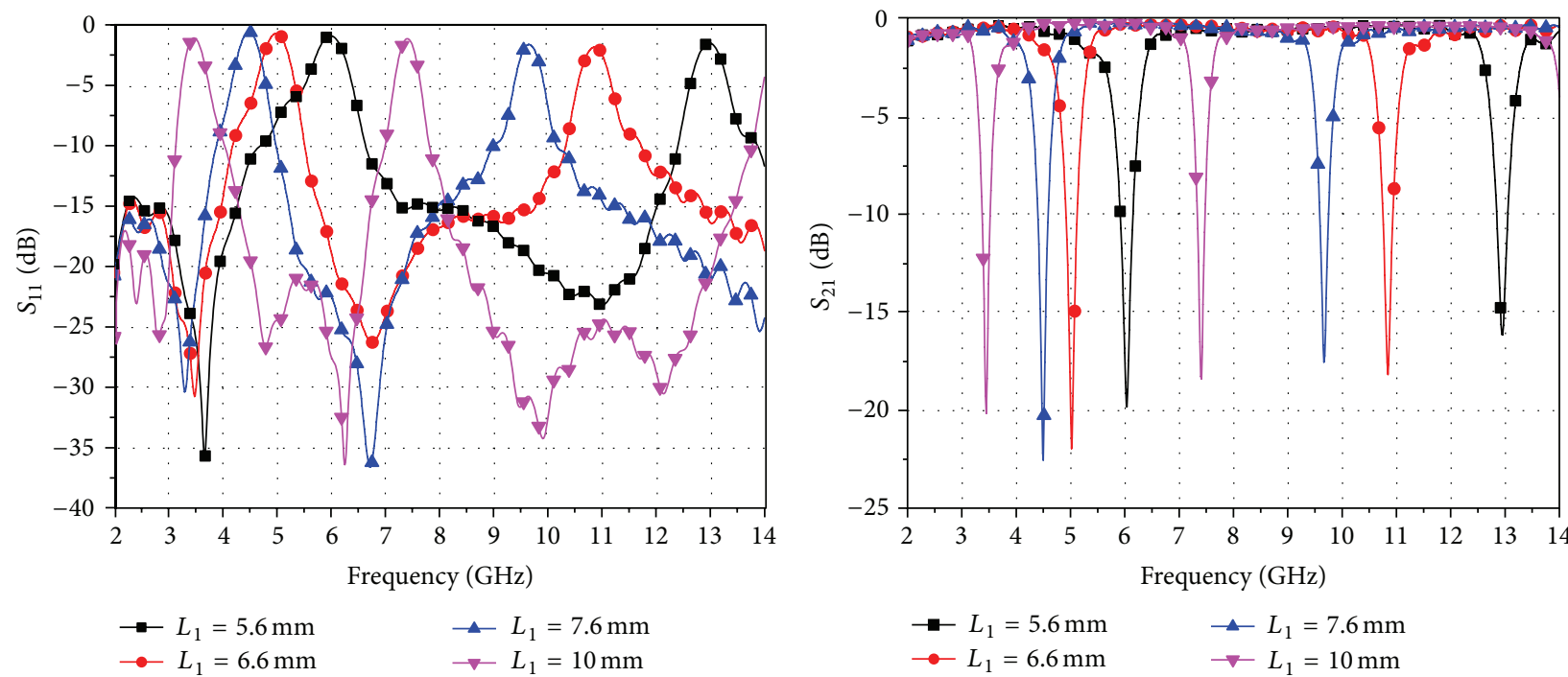

(a) $S_{11}$ of DMS-BSF with varying $L_{1}$

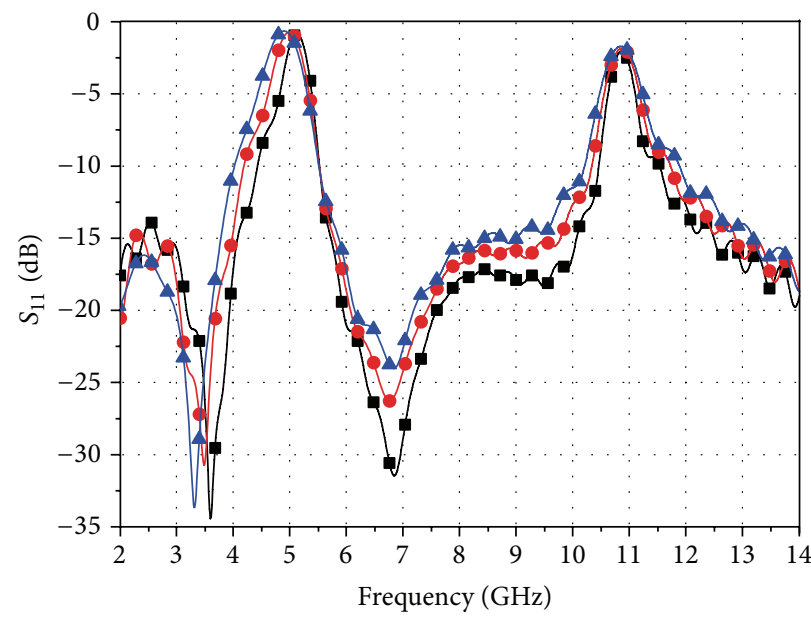

$\begin{aligned} \because g & =0.4 \mathrm{~mm} \\ \rightarrow g & =0.5 \mathrm{~mm}\end{aligned} \quad \sim g=0.6 \mathrm{~mm}$

(c) $S_{11}$ of DMS-BSF with varying $g$

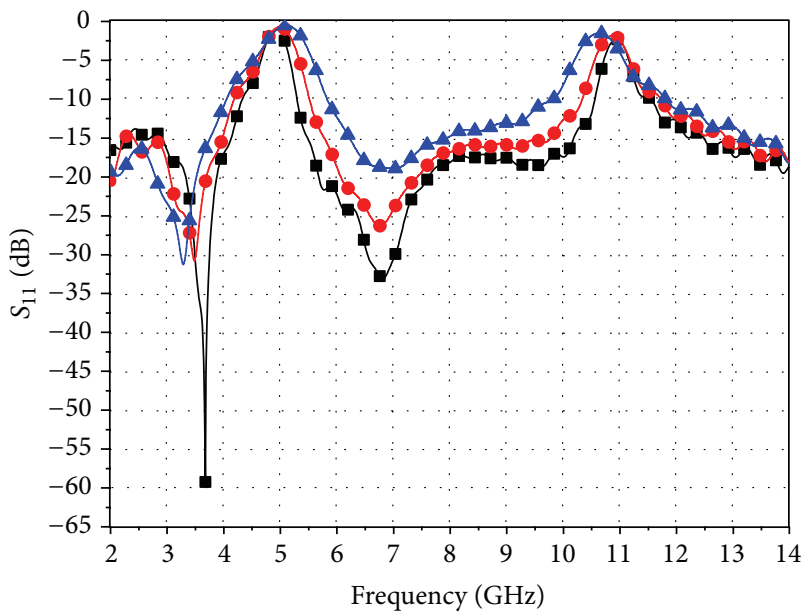

$$
\begin{aligned}
\longrightarrow g_{1} & =0.3 \mathrm{~mm} \\
\rightarrow g_{1} & =0.4 \mathrm{~mm}
\end{aligned} \quad \longrightarrow g_{1}=0.5 \mathrm{~mm}
$$

(e) $S_{11}$ of DMS-BSF with varying $g_{1}$

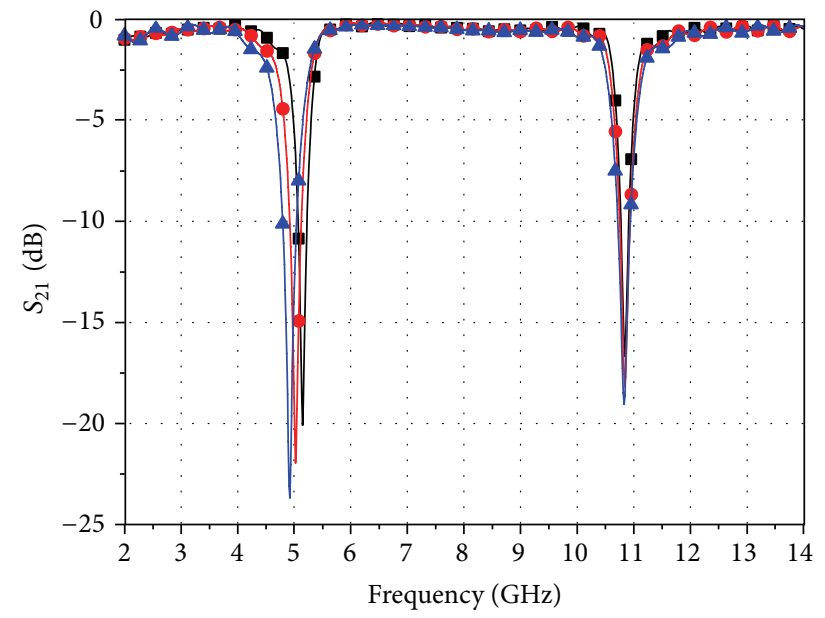

(b) $S_{21}$ of DMS-BSF with varying $L_{1}$

$$
\rightarrow g=0.4 \mathrm{~mm}
$$

(d) $S_{21}$ of DMS-BSF with varying $g$

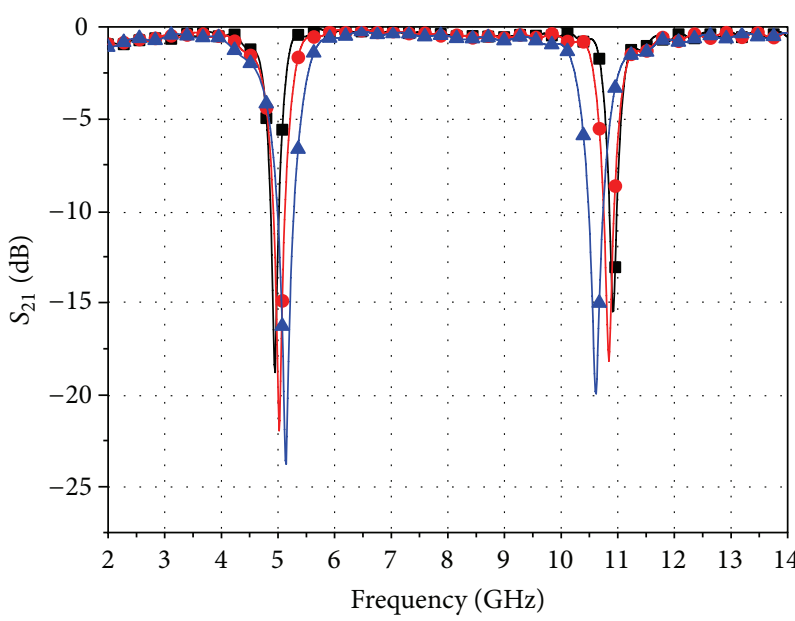

$$
\begin{aligned}
& \because g_{1}=0.3 \mathrm{~mm} \\
& \because g_{1}=0.4 \mathrm{~mm}
\end{aligned} \quad \longrightarrow g_{1}=0.5 \mathrm{~mm}
$$

(f) $S_{21}$ of DMS-BSF with varying $g_{1}$ 


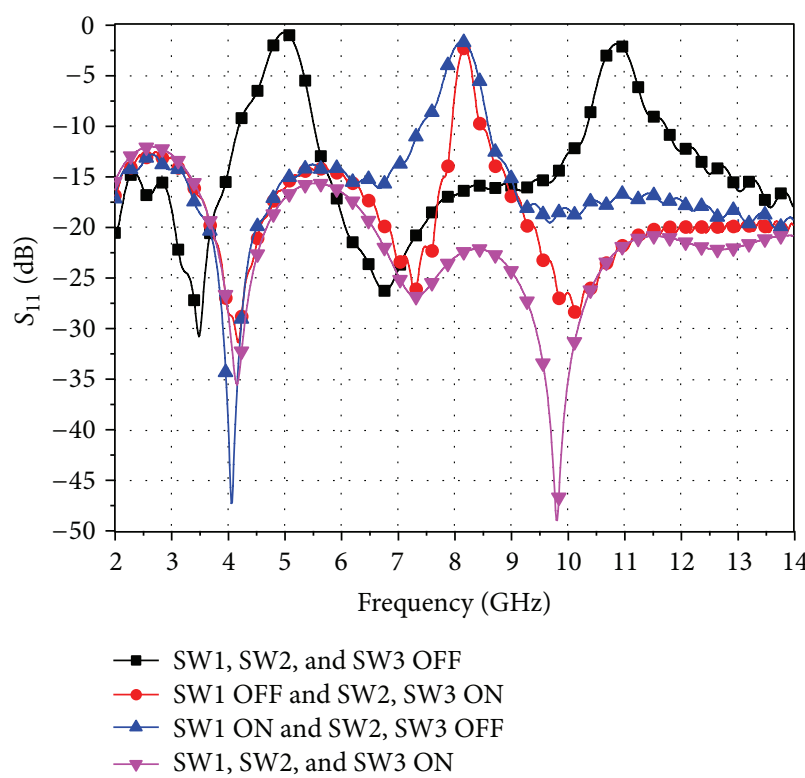

(g) $S_{11}$ of DMS-BSF switchable functions

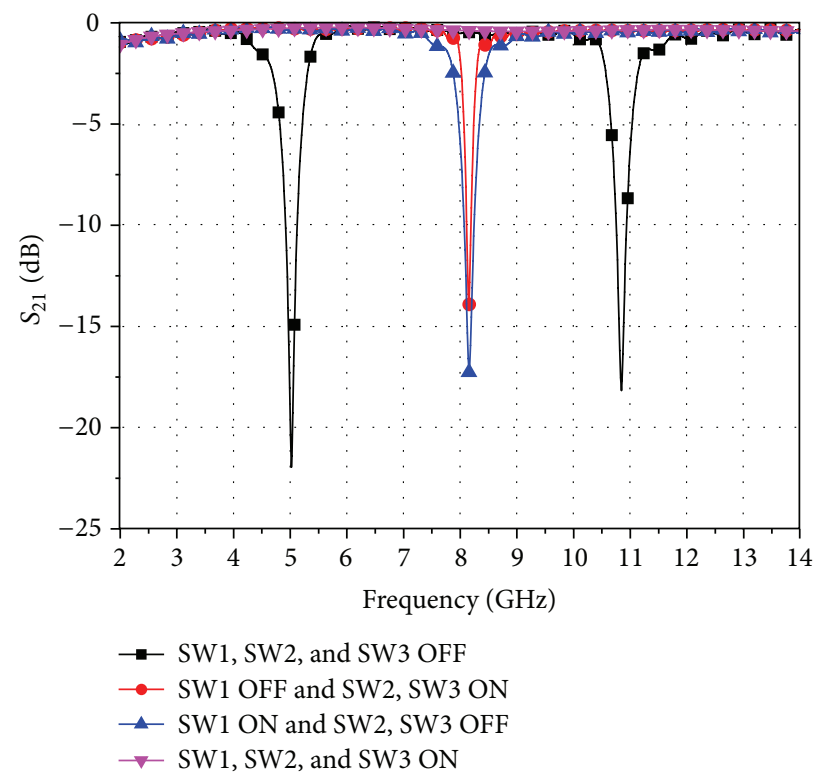

(h) $S_{21}$ of DMS-BSF switchable functions

FIGURE 2: $S$-parameters of DMS-BSF.

which will produce interference to other microwave elements [24]. PBGs and EBGs have many parameters which make them difficult to design. In addition, PBG/EBG parameters also affect the band gap characteristic [23]. On the other hand, the defected microstrip structure (DMS) is of great advantages in design due to its reduced size and the feature of electromagnetic interference (EMI) noise immunity [24-29]. Furthermore, DMS has higher effective inductance compared to DGS [26], PBG, and EBG. Therefore, DMS has been used for designing filters, reducing antenna size, and suppressing the crosstalk of parallel microstrip lines [23, 24, 29]. In this paper, a meander line DMS is employed to design a multimode band-notched UWB antenna. The configuration of DMS-BSF is designed and illustrated in Figure 1, and its performance is investigated using CST.

From Figure 1, we can see that the DMS-BSF consists of a $50 \Omega$ microstrip line with width $W$ and a meander slot with parameters $L_{1}, g$, gap, and $g_{1}$. Detailed meander slot parameters are shown in Figure 1(b). In order to design a switchable DMS-BSF, three ideal switches are incorporated into the meander slot. The three switches are described as SW1, SW2, and SW3 and shown in Figure 1(c). In general, horizontal slots of the meander slot provide inductance effects, while vertical slots exhibit capacitive characteristics [25]. Thus, the resonant frequency can be adjusted by controlling dimensions of the meander slot. To investigate the characteristics of DMS-BSF, various parameters are analyzed using CST. DMSBSF is printed on a substrate with a dielectric constant of 2.65 , a loss tangent of 0.002 , and a thickness of $h=1.6 \mathrm{~mm}$, and the dimensions are $L_{1}=6.6 \mathrm{~mm}$, gap $=g=0.5 \mathrm{~mm}$, and $g_{1}=0.4 \mathrm{~mm}$. In the simulation, one parameter is varied, while others remain fixed. The reflection coefficient $\left(S_{11}\right)$ and transmission coefficient $\left(S_{21}\right)$ of DMS-BSF are illustrated in Figure 2. Figures 2(a) and 2(b) show effects of varying $L_{1}$, and we can see that the DMS-BSF exhibits dual-band band stop characteristics in frequency response. As $L_{1}$ increases, the first resonance shifts down slowly to the lower frequencies, while the second resonance moves fast toward lower frequencies. This is because the DMS increases the electric length of the microstrip line and hence changes its current distribution and the effective capacitance and inductance. The increased horizontal length of the meander slot affects the structure inductively [25]. The first resonant frequency has a wide tuning stop band which ranges from $3.5 \mathrm{GHz}$ to $6 \mathrm{GHz}$, while the second one can adjust from $7.4 \mathrm{GHz}$ to $12.9 \mathrm{GHz}$. Figures 2(c) and 2(d) demonstrate $S_{11}$ and $S_{21}$ in terms of varying $g$. By changing $g$ from $0.4 \mathrm{~mm}$ to $0.6 \mathrm{~mm}$, the center frequency of the first resonance moves to lower band, while the second resonant frequency keeps constant. The characteristics of $S_{11}$ and $S_{21}$ when varying $g_{1}$ are shown in Figures 2(e) and 2(f). With the increase of $g_{1}$, the center frequency of the first resonance moves to higher band. On the contrary, the center frequency of the second resonance slightly shifts toward lower frequencies. In addition, the pass band characteristics are also deteriorated with the increase of $g_{1}$. The switching characteristics are shown in Figures 2(g) and $2(\mathrm{~h})$. In this simulation, the ideal switches are replaced with three metal strips with length $0.5 \mathrm{~mm}$ and width $0.4 \mathrm{~mm}$. It is obvious that DMS-BSF has two stop bands with all switches OFF. The center frequency of the two stop bands can be controlled by adjusting the dimensions of the meander slot. When SW1 is ON and SW2 and SW3 are OFF, the DMSBSF has only one stop band which is near $8 \mathrm{GHz}$. For SW1 OFF and SW2 and SW3 ON, the DMS-BSF also has one stop band. However, the stop band characteristics are different for these two situations. The DMS-BSF with SW1 ON and both SW2 and SW3 OFF has wider stop band than the DMS-BSF with SW1 OFF and both SW2 and SW3 ON. When all the 


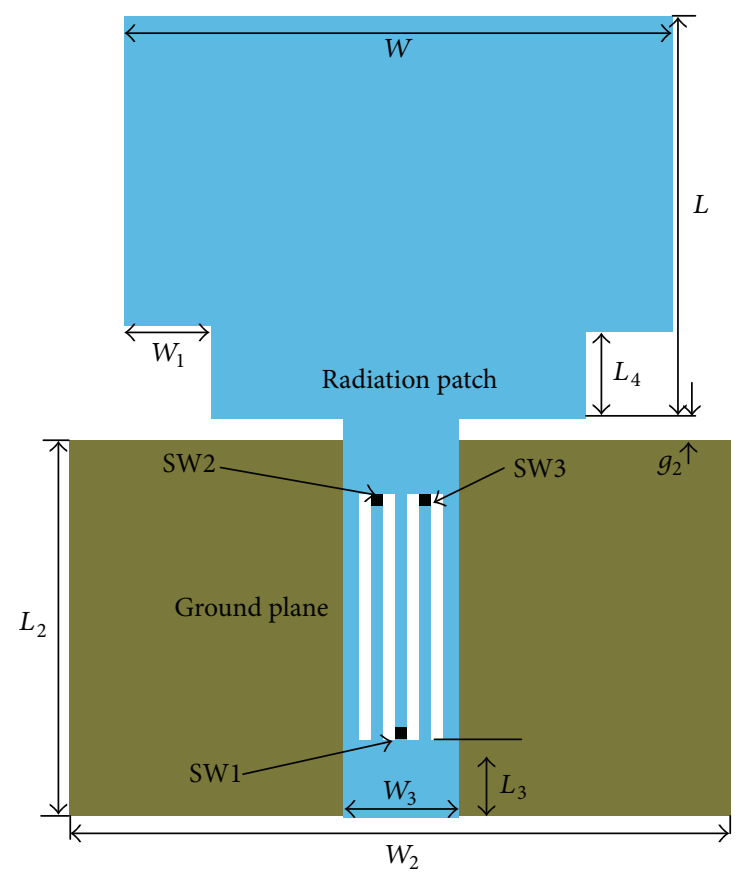

Figure 3: Cognitive radio antenna A.

switches are ON, the proposed structure is an all-pass filter which passes all frequency. As can be seen from Figure 2, the meander slot DMS-BSF has dual resonant frequency, while conventional structure has only one resonance [24]. The switchable meander slot DMS-BSF also has tunable functions which can work in all-pass mode, a stop band mode, and dual stop band mode.

2.2. Design of Cognitive Radio Antenna A (CRA_A). A CRA should have reconfigurable characteristics for meeting the cognitive radio requirement. In cognitive radio (CR) communication systems, unlicensed users (secondary users) can access spectrum bands licensed to primary users at spectrum underlay mode or spectrum overlay mode. In the underlay mode, the secondary users are limited under a very low transmission power which is less than $-41.3 \mathrm{dBm} / \mathrm{MHz}$ for UWB users $[1,19]$. This approach can be realized by using impulse radio (IR) based UWB (IR-UWB) technology. For the overlay mode, the secondary users detect the existing narrow band (NB) signals, such as those from WLAN and RFID, and provide immunity to the NB systems. This can be implemented by turning off the corresponding subcarriers in orthogonal frequency division multiplexing (OFDM) UWB (OFDM-UWB), depending on whether any primary users exist or not in a particular band. In other words, the transmission spectrum of UWB radios can be sculpted according to the presence of the primary users in the respective frequency bands in the environment [30]. Therefore, in CRUWB systems, CRA should cover the entire UWB band from $3.1 \mathrm{GHz}$ to $10.6 \mathrm{GHz}$ with no notch bands for underlay applications and for detecting the licensed primary users and providing immunity to these users using band-notched technologies [19].

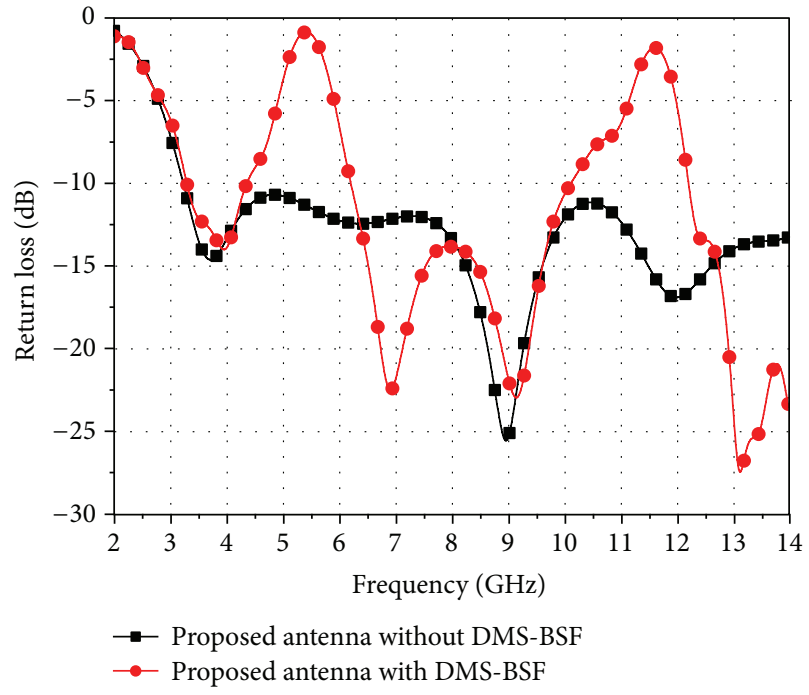

FIGURE 4: Return loss of CRA_A with all switches OFF with/without DMS-BSF

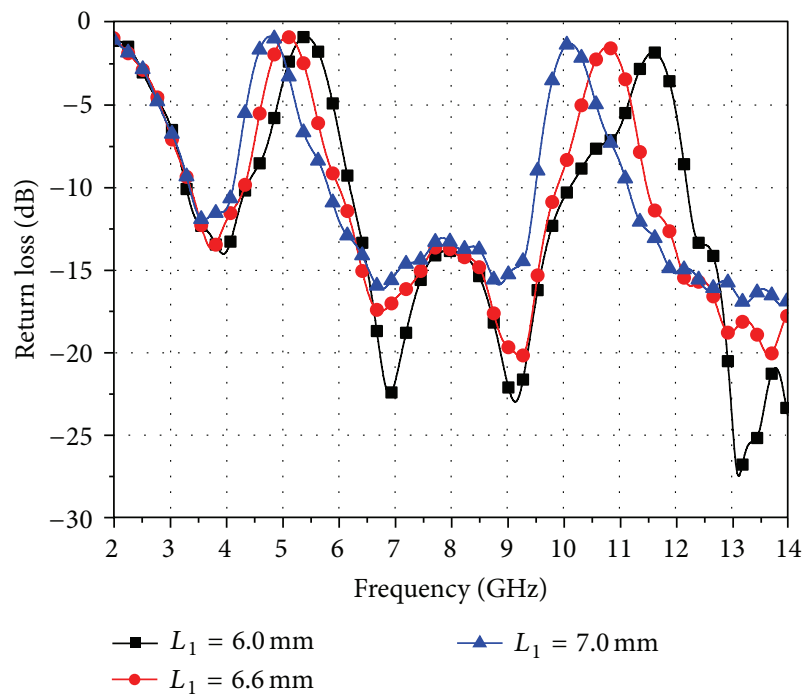

FIGURE 5: Tunable band-notched characteristics of CRA_A with all switches OFF.

Based on the investigation of meander slot DMS-BSF and the requirements for CRAs, a CRA integrated with the meander slot DMS-BSF has been proposed and shown in Figure 3. The configuration of CRA_A is printed on a substrate with a dielectric constant of 2.65 , a loss tangent of 0.002 , and a thickness of $h=1.6 \mathrm{~mm}$. CRA_A consists of a rectangular radiation patch, two square tapers at the bottom of the patch with dimensions $L_{4}$ and $W_{1}$, a DMS-BSF etched in microstrip feed line, a partial ground plane, and a $50 \Omega$ microstrip line. The radiation patch and the microstrip feed line are printed on top of the substrate, while the ground plane is printed on the bottom of the substrate. The dimensions of the antenna are optimized and listed as follows: $L=15 \mathrm{~mm}$, $W=16 \mathrm{~mm}, W_{1}=2 \mathrm{~mm}, W_{2}=30 \mathrm{~mm}, W_{3}=4.7 \mathrm{~mm}$, $L_{2}=16.2 \mathrm{~mm}, L_{3}=3.7 \mathrm{~mm}, L_{4}=2.2 \mathrm{~mm}$, and $g_{2}=0.8 \mathrm{~mm}$. 


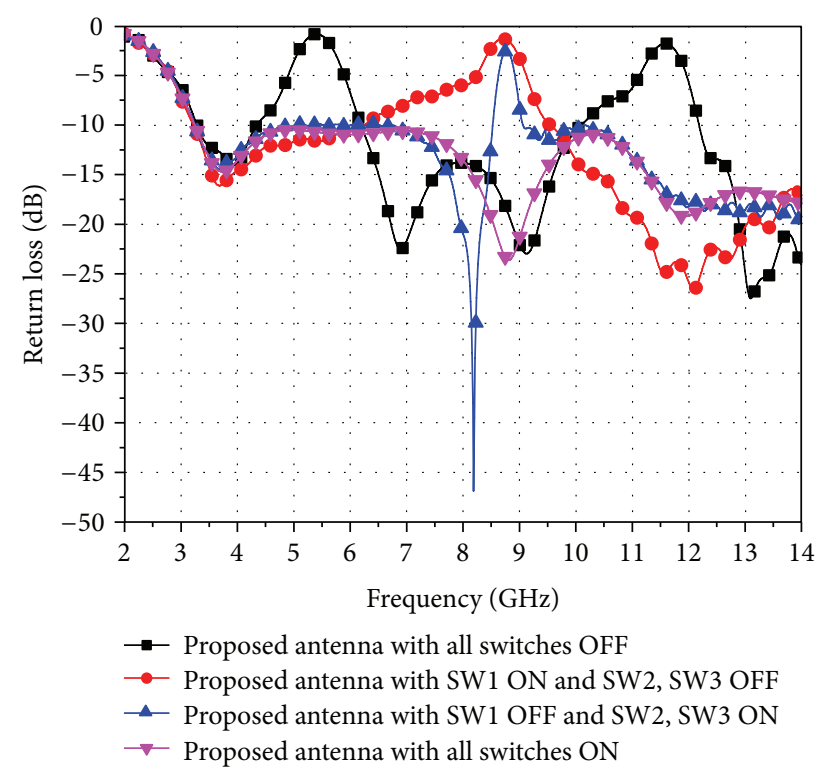

FIgURE 6: Return loss of switchable characteristics of CRA_A.

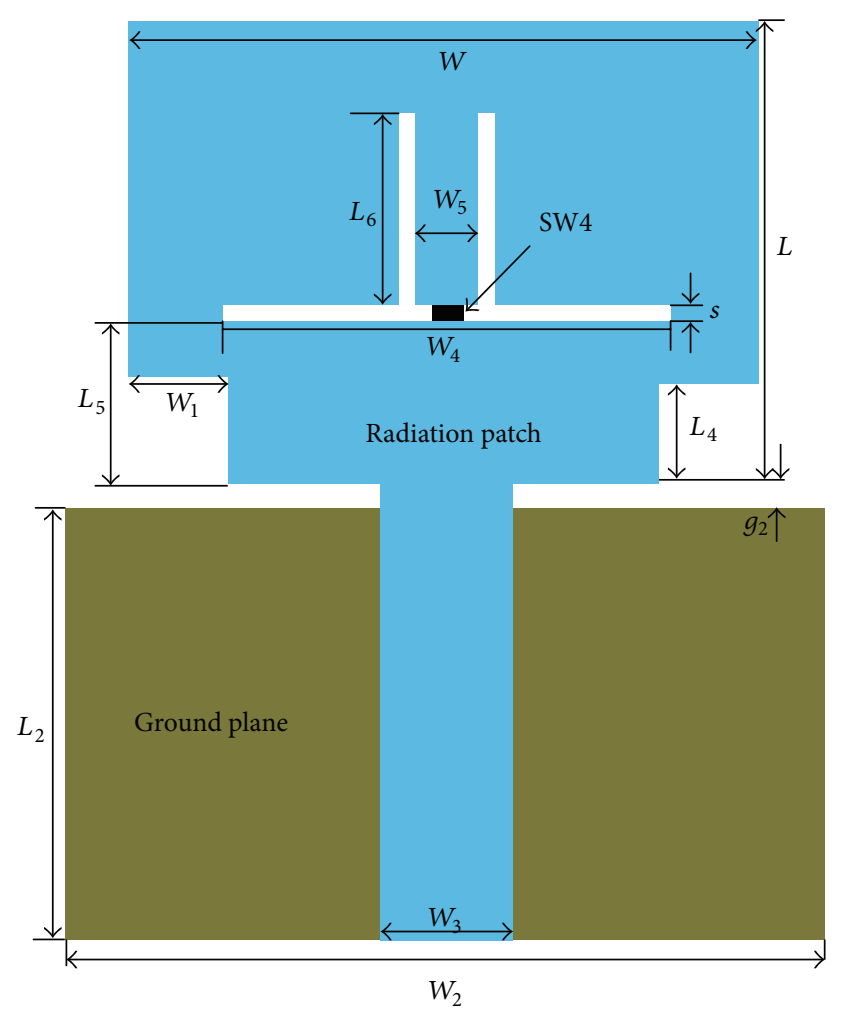

FIGURE 7: Structure of proposed CRA_B.

The dimensions of DMS-BSF of CRA_A are $L_{1}=6.6 \mathrm{~mm}$, gap $=g=0.5 \mathrm{~mm}$, and $g_{1}=0.4 \mathrm{~mm}$.

In order to investigate the performance of CRA_A, it is evaluated and analyzed using CST. The return losses of CRA_A with and without DMS-BSF are simulated and illustrated in Figure 4. It can be seen that CRA_A without DMS-BSF is a UWB antenna having bandwidth ranging from

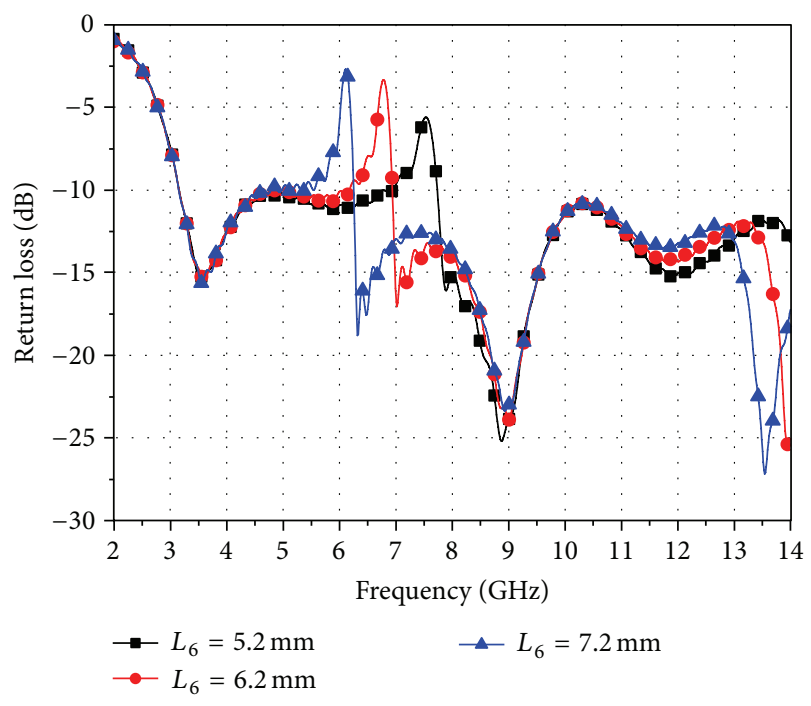

FIgURE 8: Tunable band-notched characteristics of CRA_B.

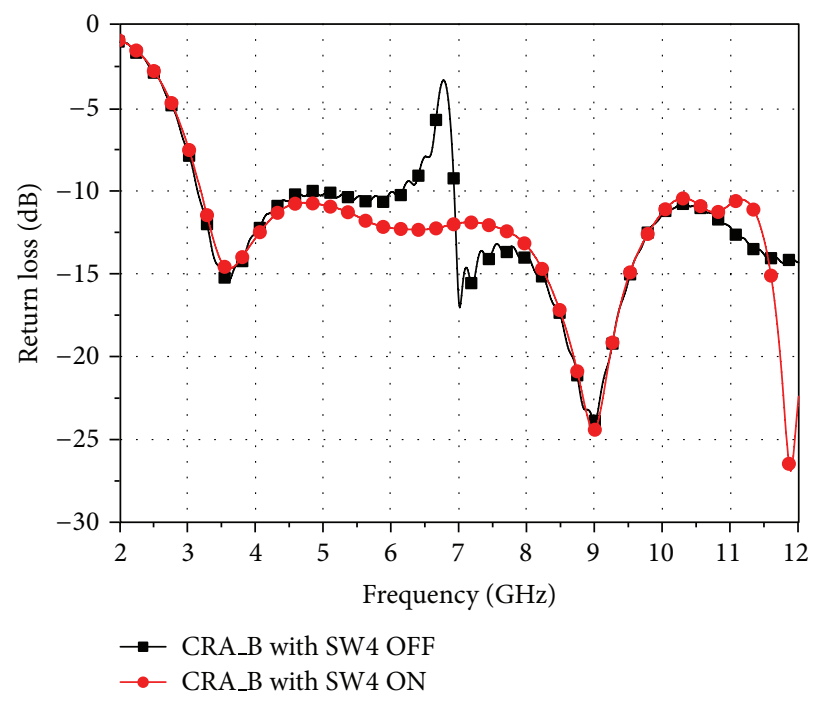

FIGURE 9: Reconfigurable characteristics of CRA_B.

3.1 GHz to $14 \mathrm{GHz}$. CRA_A with DMS-BSF has two stop bands near $5.5 \mathrm{GHz}$ and $11.5 \mathrm{GHz}$, respectively. The two notched bands are generated by DMS-BSF which changes the distributive inductance and capacitance of the microtrip feed line. This also alters the current path on the microtrip feed line. For comparison, the tuning band-notched characteristics of CRA_A with all switches OFF are analyzed and shown in Figure 5. We can see that both of the notched bands move to lower frequencies by increasing $L_{1}$. The lower notched band near $5 \mathrm{GHz}$ shifts slowly, while the higher notched band near $10.5 \mathrm{GHz}$ shifts faster. In addition, the CRA_A works as a tunable band-notched antenna by altering the parameters of DMS-BSF. It is also a UWB antenna with two stop bands which can reduce or avoid EMI between broadband wireless systems and narrow band 


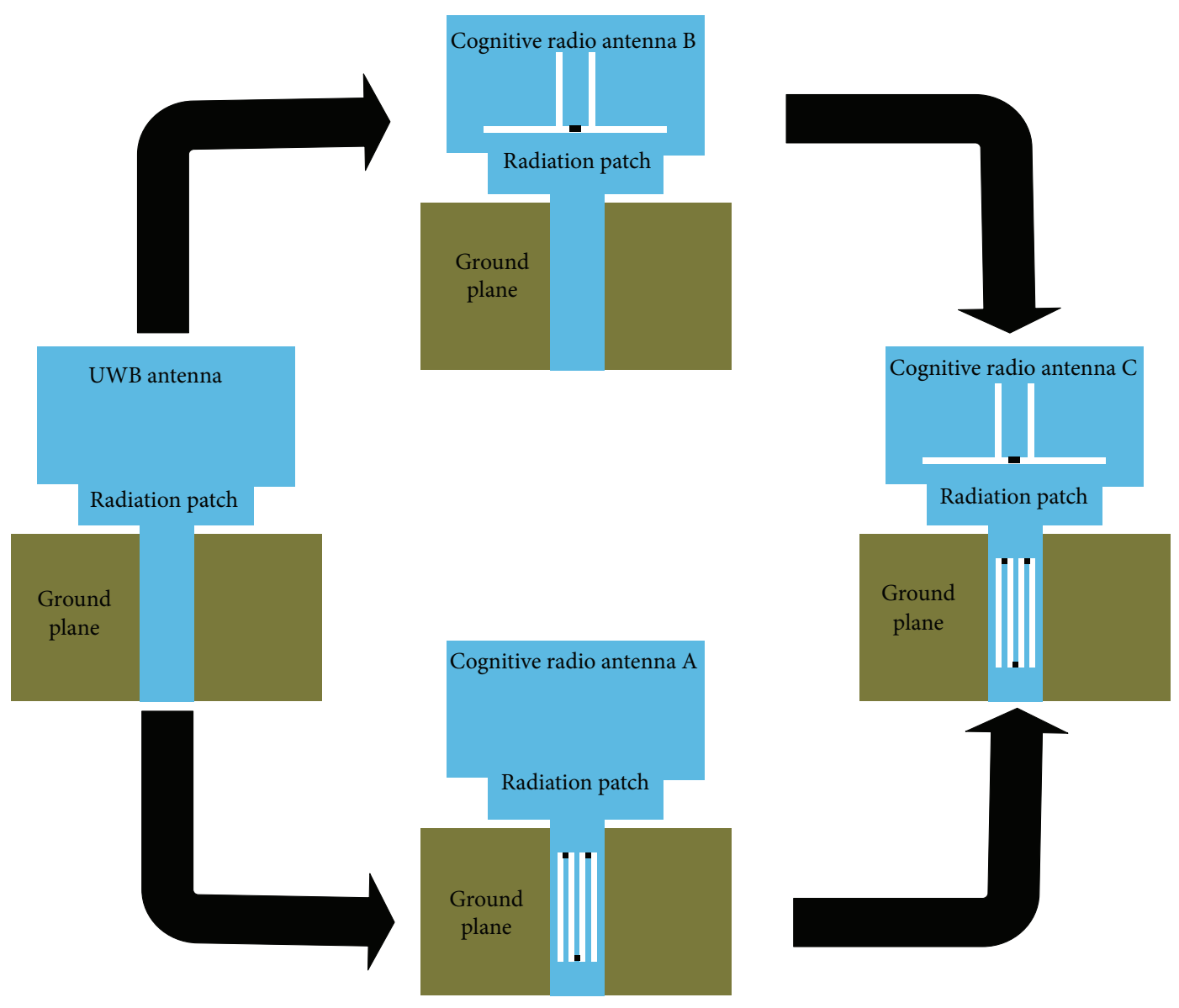

FIGURE 10: Design procedure of CRA_C.

communication systems. This antenna can also be used for tri-band wireless communication applications.

To meet the requirement of CR communication applications, the switchable characteristics of CRA_A have been studied, and the simulated results are illustrated in Figure 6. We can see that CRA_A has two notched bands near $5.5 \mathrm{GHz}$ and $11.5 \mathrm{GHz}$ with all switches OFF. In order to balance the feed line, SW2 and SW3 turn on or off simultaneously. When SW1 is ON and SW2 and SW3 are OFF, CRA_A has a notch near $8.8 \mathrm{GHz}$ and the bandwidth covers $6.2 \mathrm{GHz}$ to $9.5 \mathrm{GHz}$. When SW1 is OFF and SW2 and SW3 are ON, CRA_A also has a notch near $8.8 \mathrm{GHz}$, but the bandwidth is narrower with only about $0.5 \mathrm{GHz}$. The notched bands help to prevent the potential interference to a primary user or the services operated in these bands. When all the switches are $\mathrm{ON}$, CRA_A is a UWB antenna for underlay CR operation and for channel sensing in overlay CR scenario.

2.3. Design of Cognitive Radio Antenna B (CRA_B). To make the proposed CRA more useful for practical applications, CRA_B is designed by etching an inverted $\pi$-shaped slot in the radiation patch. The structure of CRA_B is illustrated in Figure 7. CRA_B is printed on a substrate with a dielectric constant of 2.65, a loss tangent of 0.002 , and a thickness of $h=1.6 \mathrm{~mm}$. CRA_B consists of a rectangular radiation patch, two square tapers at the bottom of the patch with dimensions $L_{4}$ and $W_{1}$, an inverted $\pi$-shaped slot embedded in the rectangular radiation patch, a partial ground plane, and a $50 \Omega$ microstrip line. The radiation patch and the microstrip feed line are printed on top of the substrate, while the ground plane is printed on the bottom of the substrate. The dimensions of CRA_B are optimized and listed as follows: $L=15 \mathrm{~mm}, W=16 \mathrm{~mm}, W_{1}=2 \mathrm{~mm}, W_{2}=30 \mathrm{~mm}$, $W_{3}=4.7 \mathrm{~mm}, W_{4}=9 \mathrm{~mm}, W_{5}=3.2 \mathrm{~mm}, L_{2}=16.2 \mathrm{~mm}$, $L_{4}=2.2 \mathrm{~mm}, L_{5}=4.1 \mathrm{~mm}, L_{6}=6.2 \mathrm{~mm}$, and $g_{2}=0.8 \mathrm{~mm}$. The width of the inverted $\pi$-shaped slot is $s=0.4 \mathrm{~mm}$. In the simulation of CRA_B, the switch 4 (SW4) is a metal strip with length of $0.6 \mathrm{~mm}$ and width $0.4 \mathrm{~mm}$. This piece of metal strip is approximated as an ideal switch which has been used in the design of most of reconfigurable antennas.

The effects of $L_{6}$ of the inverted $\pi$-shaped slot with switch $4 \mathrm{OFF}$ are shown in Figure 8. It can be seen that the CRA_B has a notched band near $6.8 \mathrm{GHz}$ which is used for RFID devices. The center frequency of the notched band is tunable by adjusting the dimensions of the inverted $\pi$ shaped slot. The notched band moves to lower frequencies with the increase of $L_{6}$. In order to reduce the potential interference from RFID systems, the length is set as $6.2 \mathrm{~mm}$. Other parameters that have little effect on the notched band are not analyzed. In order to make the CRA_B reconfigurable, 


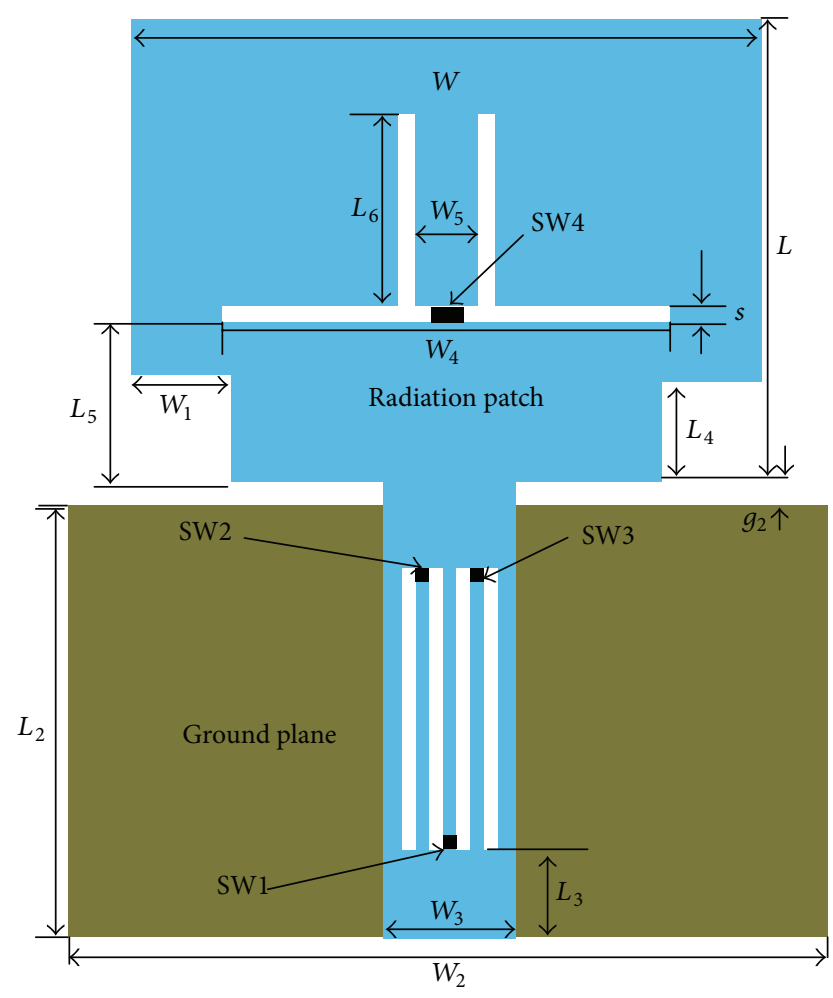

Figure 11: Geometry of CRA_C.

a switch SW4 is used on the inverted $\pi$-shaped slot. The dimensions of SW4 are length of $0.6 \mathrm{~mm}$ and width of $0.4 \mathrm{~mm}$. The reconfigurable characteristics of CRA_B are investigated and shown in Figure 9. For the case of SW4 OFF, CRA_B has a notched band in the RFID band, and the center frequency can be adjusted by changing the length of $L_{6}$. This is due to the fact that changing the length of the inverted $\pi$ shaped slot alters the resonant length which corresponds to the resonant frequency. The CRA_B with SW4 OFF can be used in the overlay mode. When the SW4 is ON, the CRA_B is a UWB antenna and can be used in the underlay mode for channel sensing.

2.4. Design of Cognitive Radio Antenna C (CRA_C). Based on the studies of CRA_A and CRA_B, CRA_C integrated with DMS-BSF in CRA_A and the inverted $\pi$-shaped slot used in CRA_B has been proposed numerically and experimentally. Design procedures of CRA_C are shown in Figure 10. Firstly, a UWB antenna is designed. Secondly, a DMS-BSF is embedded in the microstrip feed line of the proposed UWB antenna to generate two notched bands for reducing or avoiding potential EMI from WLAN, WiMAX, and Xband, which is CRA_A. Thirdly, an inverted $\pi$-shaped slot is etched in the radiation patch of the UWB antenna to produce another notched bands for preventing the potential EMI from RFID systems, which is CRA_B. Finally, DMS-BSF and the inverted $\pi$-shaped slot are incorporated into the UWB antenna to form CRA_C which is shown in Figure 11. CRA_C is the combination of CRA_A and CRA_B.

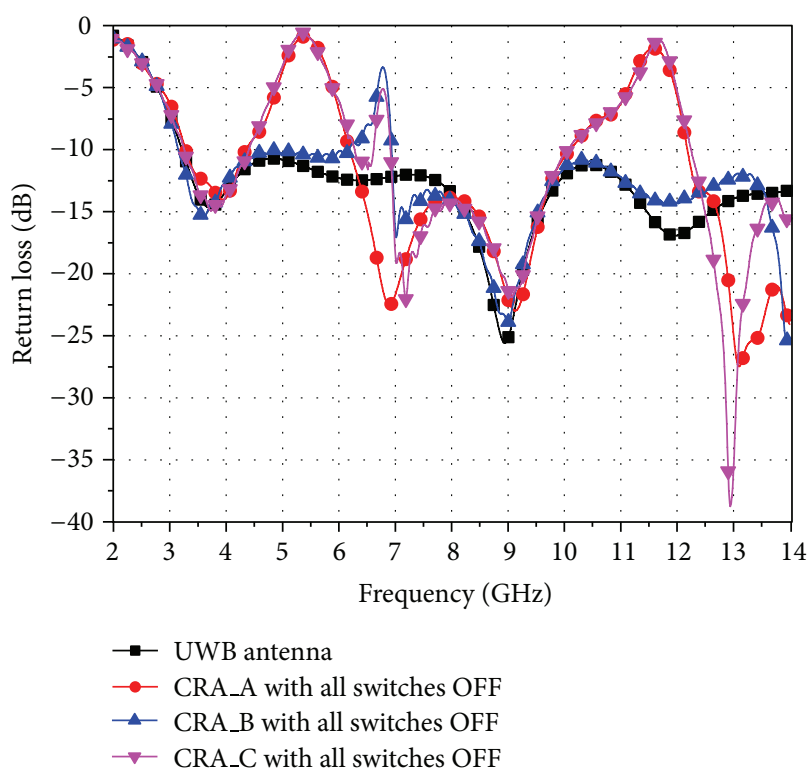

FIGURE 12: Comparisons of proposed cognitive radio antennas with all switches OFF.

TABLE 1: Eight switchable cases and corresponding notch bands.

\begin{tabular}{lccccc}
\hline Case & Notch bands $(\mathrm{GHz})$ & SW1 & SW2 & SW3 & SW4 \\
\hline 1 & $5.5,6.8,11.5$ & OFF & OFF & OFF & OFF \\
2 & $5.5,11.5$ & OFF & OFF & OFF & ON \\
3 & 8.7 & ON & OFF & OFF & ON \\
4 & 8.7 & OFF & ON & ON & ON \\
5 & $6.8,8.7$ & ON & OFF & OFF & OFF \\
6 & $6.8,8.7$ & OFF & ON & ON & OFF \\
7 & 6.8 & ON & ON & ON & OFF \\
8 & None (UWB antenna) & ON & ON & ON & ON \\
\hline
\end{tabular}

The dimensions of CRA_C are optimized and listed as follows: $L=15 \mathrm{~mm}, W=16 \mathrm{~mm}, W_{1}=2 \mathrm{~mm}, W_{2}=30 \mathrm{~mm}$, $W_{3}=4.7 \mathrm{~mm}, W_{4}=9 \mathrm{~mm}, W_{5}=3.2 \mathrm{~mm}, L_{2}=16.2 \mathrm{~mm}$, $L_{3}=3.7 \mathrm{~mm}, L_{4}=2.2 \mathrm{~mm}, L_{5}=4.1 \mathrm{~mm}, L_{6}=6.2 \mathrm{~mm}, g_{2}=$ $0.8 \mathrm{~mm}$, and $s=0.4 \mathrm{~mm}$. The dimensions of DMS-BSF of CRA $\_$are $L_{1}=6 \mathrm{~mm}$, gap $=g=0.5 \mathrm{~mm}$, and $g_{1}=0.4 \mathrm{~mm}$. For comparison, return losses of the UWB antenna, CRAA, CRA_B, and CRA_C are plotted and shown in Figure 12, where all the switches are OFF. It can be seen that the UWB antenna can work in a wide bandwidth ranging from $3.1 \mathrm{GHz}$ to $14 \mathrm{GHz}$. The proposed CRA_C has three notched bands which are the combined results of CRA_A and CRA_B. The center frequencies of the three notched bands agree well with CRA_A and CRA_B. In addition, the notched band at $6.8 \mathrm{GHz}$ and the other notched bands can be adjusted by changing the dimensions of the inverted $\pi$-shaped slot and DMS-BSF, respectively.

As a CRA, CRA_C should be reconfigurable so that it can work in cognitive radio environment. Therefore, CRA_C is investigated for eight possible operation modes which are listed in Table 1. Return losses of these eight cases are 


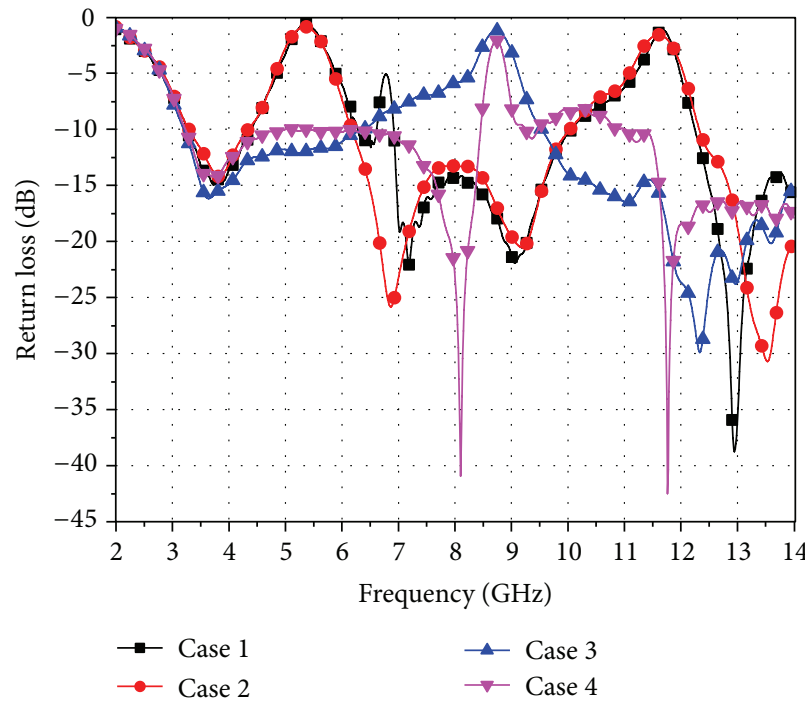

(a)

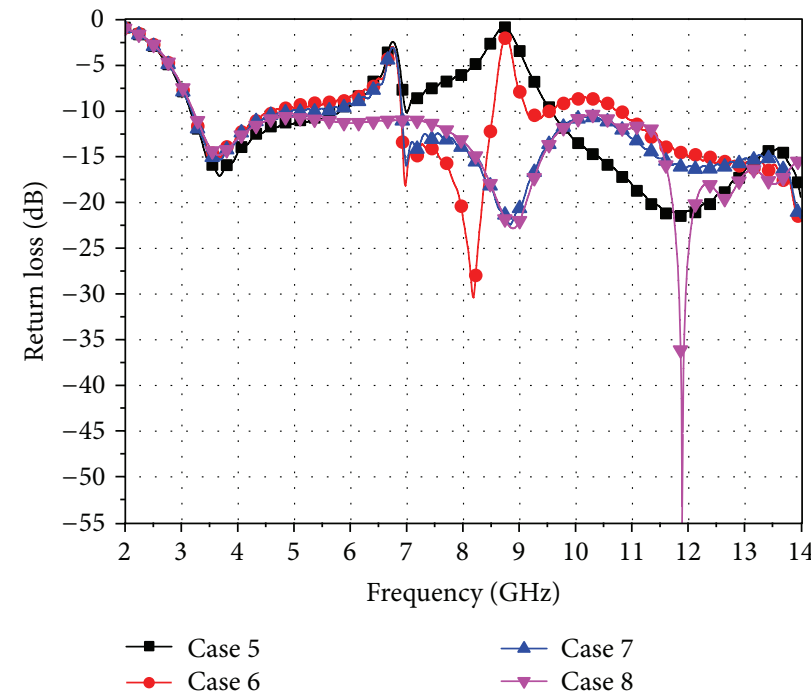

(b)

FIGURE 13: Switchable characteristics of CRA_C with various cases.

demonstrated in Figure 13. For case 1, CRA_C is a UWB antenna with triple notched bands which can prevent the interference from licensed primary users. In case 1, CRA_C can be used as a CRA in overlay mode. CRA_C in case 1 can also be used as a multiband antenna which works at $3.1 \mathrm{GHz}-$ $4.2 \mathrm{GHz}, 6.2 \mathrm{GHz}-6.6 \mathrm{GHz}, 7.0 \mathrm{GHz}-10 \mathrm{GHz}$, and $12.2 \mathrm{GHz}-$ $14 \mathrm{GHz}$. When CRA_C works in case 2, case 5, and case 6 modes, it can provide two notched bands. For case 2, the two notched bands are $5.5 \mathrm{GHz}$ for reducing the interference from WLAN, WiMAX, and C-band and $11.5 \mathrm{GHz}$ for preventing the interference from X-band. As for case 5 and case 6 , the two notched bands work at $6.8 \mathrm{GHz}$ and $8.7 \mathrm{GHz}$. In these cases, CRA_C can avoid the interference from RFID and X-band, respectively. Furthermore, case 6 has a narrower notched band than case 5 . This has the similar characteristics as DMSBSF discussed in 2.1. When CRA_C works in case 3, case 4, and case 7 , it has a notched band which works at $8.7 \mathrm{GHz}$, $8.7 \mathrm{GHz}$, and $6.8 \mathrm{GHz}$, respectively. However, the bandwidth of the notched band is different. Case 3 has a wider notched band bandwidth than those of case 4 and case 7 . The bandnotched characteristics of case 3 and case 4 are determined by DMS-BSF, and those of case 7 is mainly determined by the inverted $\pi$-shaped slot. In these cases, CRA_C can work in overlay mode. For case 8, CRA_C is a UWB antenna, which can be used in underlay mode.

\section{Results and Discussions}

To verify the above design and compare with measurement, CRA_C in case 1 and case 8 are fabricated and measured. For comparison, the four ideal switches, switch 1 (SW1), switch 2 (SW2), switch 3 (SW3), and switch 4 (SW4) are also metal bridges which are replaced by a metal strip in fabrication. In simulation and fabrication, the metal bridges with dimensions of $0.5 \mathrm{~mm} \times 0.4 \mathrm{~mm}$ are used to approximate SW1, SW2, and SW3. SW4 is replaced with a metal strip with a length $0.6 \mathrm{~mm}$ and width $0.4 \mathrm{~mm}$. For reducing the cost of fabrication and measurement, CRA_C with all switches ON and OFF is fabricated and tested to verify the accuracy of CST simulations. CRA_C with all switches ON and OFF is optimized, and the optimal parameters are as follows: $L=$ $15 \mathrm{~mm}, W=16 \mathrm{~mm}, W_{1}=2 \mathrm{~mm}, W_{2}=30 \mathrm{~mm}, W_{3}=$ $4.7 \mathrm{~mm}, W_{4}=9 \mathrm{~mm}, W_{5}=3.2 \mathrm{~mm}, L_{2}=16.2 \mathrm{~mm}, L_{3}=$ $3.7 \mathrm{~mm}, L_{4}=2.2 \mathrm{~mm}, L_{5}=4.1 \mathrm{~mm}, L_{6}=6.2 \mathrm{~mm}$, and $g_{2}=$ $0.8 \mathrm{~mm}$. The dimensions of DMS-BSF are again $L_{1}=6 \mathrm{~mm}$, $g=0.5 \mathrm{~mm}$, and $g_{1}=0.4 \mathrm{~mm}$. The optimized antennas, as shown in Figure 14, are also fabricated and measured using Anritsu 37347D vector network analyzer. Measured and simulated results of return losses are compared in Figure 15.

It can be seen from Figure 15 that CRA_C with all switches $\mathrm{ON}$ is a UWB antenna which has a wide bandwidth ranging from $3.1 \mathrm{GHz}$ to $14 \mathrm{GHz}$. In this case, CRA_C can be used in underlay mode. As for CRA_C with all switches OFF, it is a UWB antenna with triple notched bands which can prevent the interference from C-band, WLAN, WiMAX, RFID, and $\mathrm{X}$-band. In case 1, CRA_C can be used for overlay mode. In addition, CRA_C in case 1 is also a four band antenna which can operate in multiband wireless communication systems. The measured results agree well with the simulated ones, which help to verify the accuracy of the simulation. The discrepancy between simulated and measured curves may be due to the errors of manufactured antennas. Thereby, we can control the switches $\mathrm{ON}$ and OFF to allow the proposed antenna to work in underlay and overlay modes for cognitive radio communications. The proposed antennas can also be used for multiband communication systems and multimode wireless communication systems by controlling the switches ON and OFF. Measured radiation patterns at $3.5 \mathrm{GHz}, 6.4 \mathrm{GHz}$, and $9.0 \mathrm{GHz}$ of case 1 and case 8 are shown in Figure 16. 


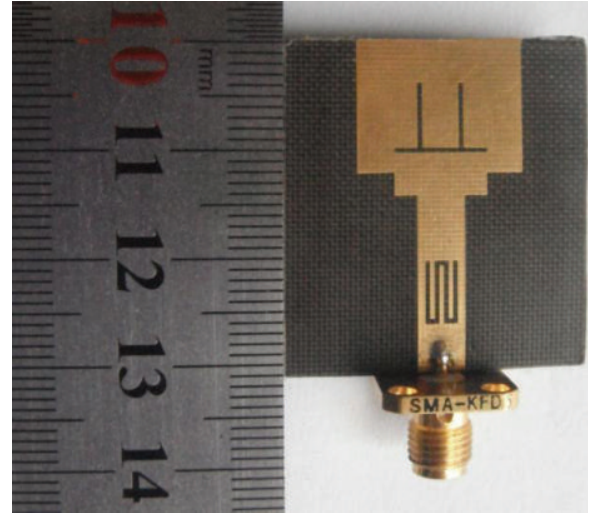

(a) Top view of fabricated antenna of case 1

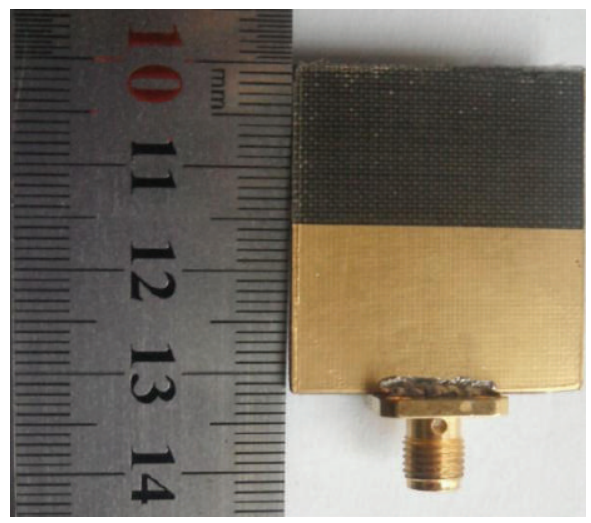

(c) Bottom view of fabricated antenna of case 1

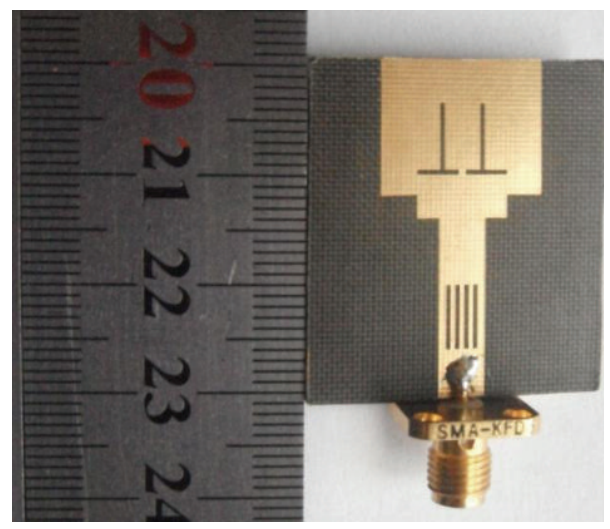

(b) Top view of fabricated antenna of case 8

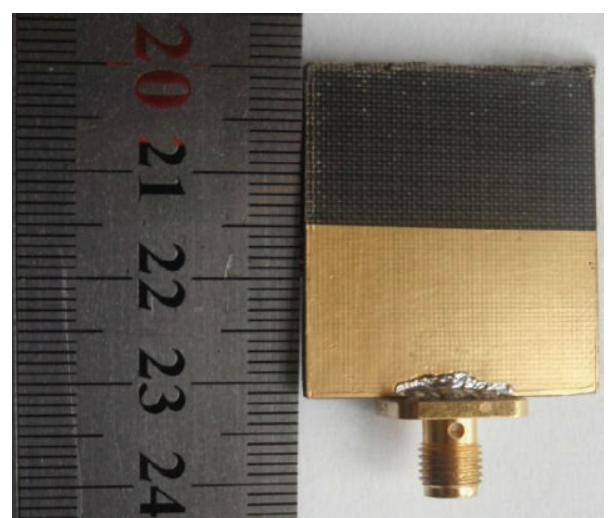

(d) Bottom view of fabricated antenna of case 8

FIgURE 14: The fabricated CRA_C in case 1 and case 8.

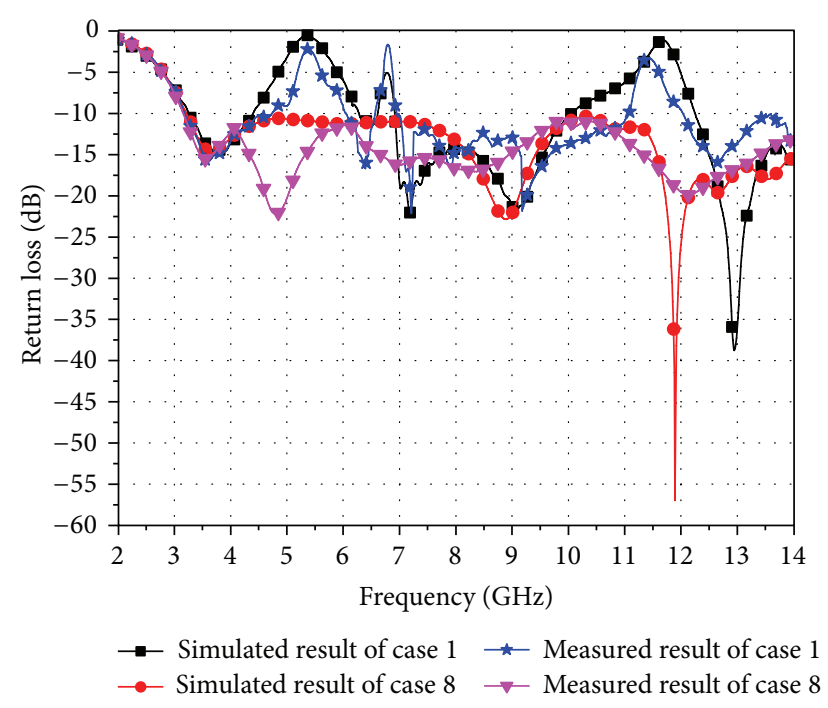

FIGURE 15: Return losses of fabricated CRA_C in case 1 and case 8.

It is worth noting that the radiation patterns of CRA_C are omnidirectional in the H-plane ( $x z$-plane) and dipole like in the E-plane ( $y z$-plane) when all the switches are turned on or off, respectively. The E-plane radiation patterns of CRA_C with all switches OFF have a little distortion, which is caused by the power leaking of the inverted $\pi$-shaped slot. It is found that the measured results of CRA_C using the DMS-BSF, the inverted $\pi$-shaped slot, and the ideal switches well satisfy the requirement of UWB cognitive radio communication applications. The peak gains of CRA_C with all switches ON or OFF are obtained by comparing with a double ridged horn antenna in the operation bands. In measuring of the gains of the fabricated antennas, only the key points in the operation bands are measured. As for CRA_C with all switches OFF, addition points are also measured in the notched bands. The measured and simulated peak gains of the fabricated antennas are illustrated in Figure 17. It is found that the stable gains of the fabricated antennas have been obtained with fluctuation less than $2.2 \mathrm{dBi}$ throughout the operation band except the three notched frequencies. As expected, CRA_C with all switches OFF has three sharp gains, which decrease in the vicinity of $5.5 \mathrm{GHz}, 6.8 \mathrm{GHz}$, and $11.5 \mathrm{GHz}$, namely, the gains drop deeply to $-2 \mathrm{dBi},-0.9 \mathrm{dBi}$, and $-0.7 \mathrm{dBi}$, respectively. However, CRA_C with all switches ON has stable gains over the UWB band. The measured gains are little lower than the simulated ones, which may be caused by the space loss of the environment for measuring the proposed low power antenna.

\section{Conclusion}

In this paper, a cognitive radio antenna integrated with DMSBSF and the inverted $\pi$-shaped slot has been investigated 


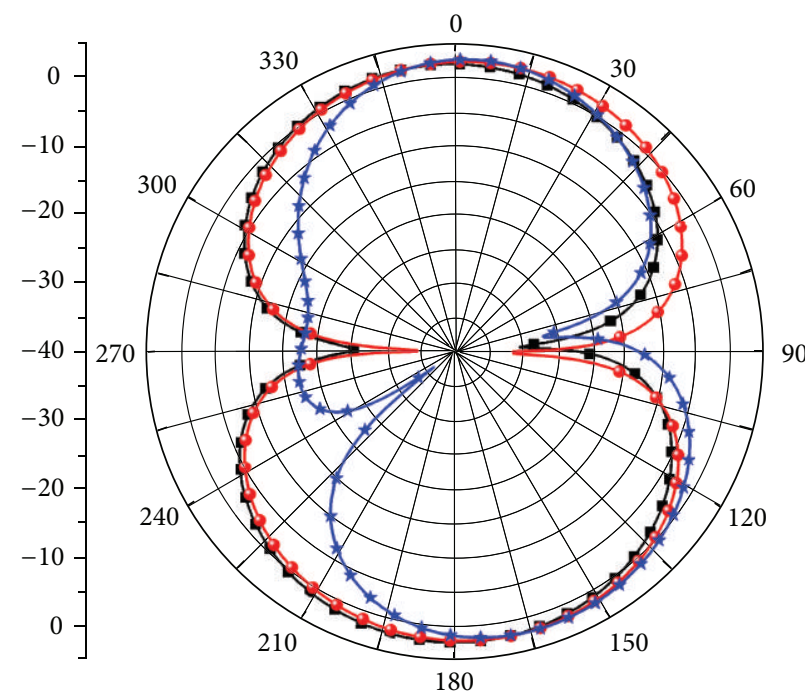

(a) E-plane of CRA_C in case 1

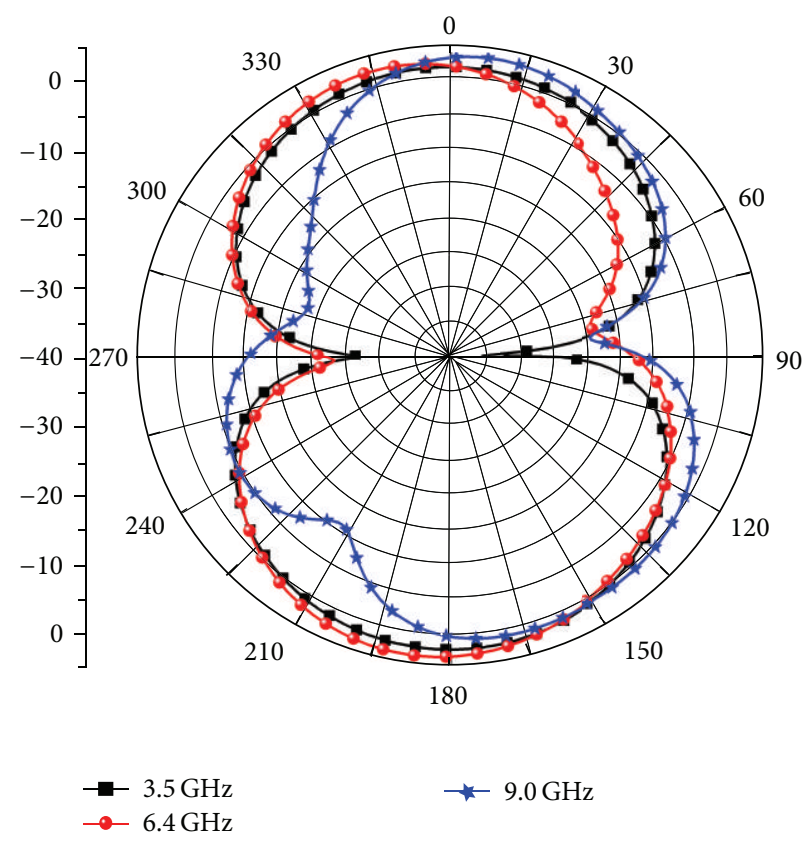

(c) E-plane of CRA_C in case 8

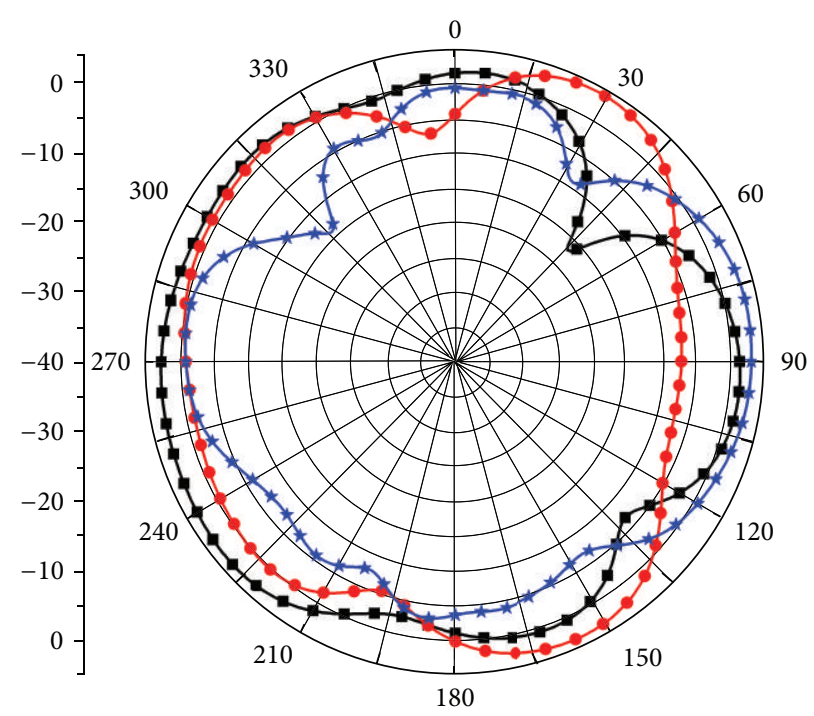

(b) H-plane of CRA_C in case 1

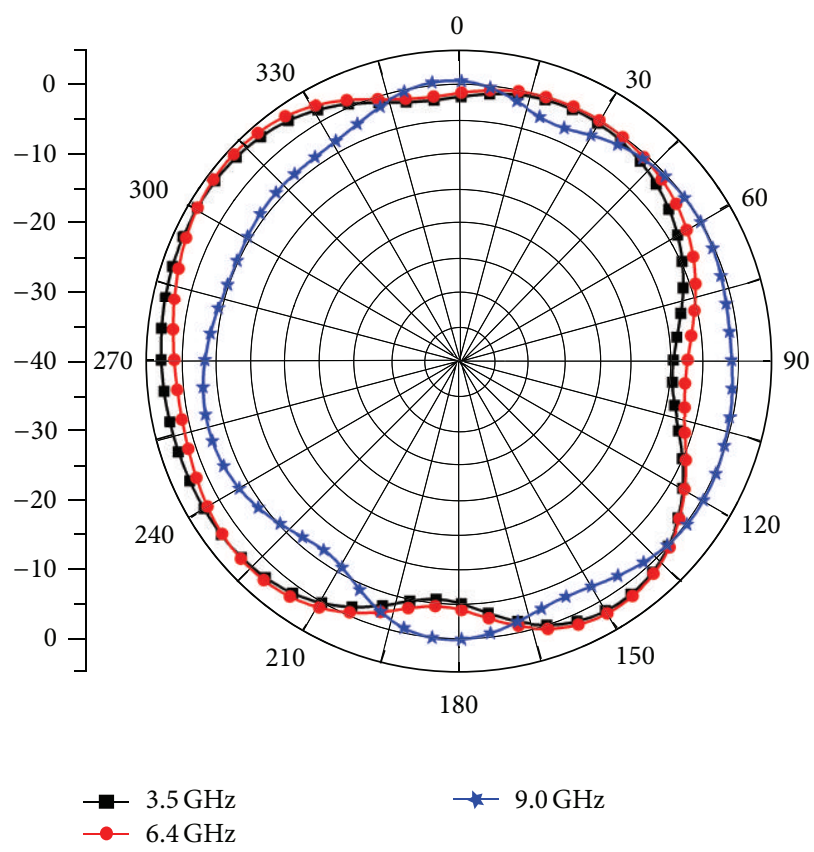

(d) H-plane of CRA_C in case 8

FIGURE 16: Measured radiation patterns of fabricated CRA_C in case 1 and case 8 .

numerically and experimentally. DMS-BSF is analyzed and discussed before CRAs design. The design procedures of proposed CRA_C are illustrated in detail through analyzing CRA_A and CRA_B separately and then combining them together. The reconfigurable functions are obtained using four ideal switches on DMS-BSF and the inverted $\pi$-shaped slot. The switchable functions and band-notched characteristics are numerically investigated. By switching ON and OFF status of the four switches, CRA_C can work in eight cases for underlay mode and overlay mode CR applications. CRA_C with all switches ON and OFF is fabricated and measured. However, the ideal switches cannot be adjusted online. In the future, we will investigate the real switches, such as PIN diodes or switch circuit networks. The impedance bandwidth, radiation patterns, and peak gains of the fabricated CRA_Cs are given and discussed. The proposed CRAs can also be used as multiband or multimode antennas. As a result, they can well meet the UWB cognitive radio communication requirement and effectively change the modes to prevent potential interference between secondary users and primary users.

\section{Acknowledgments}

This work was supported by a grant from the National Defense "973" Basic Research Development Program of 


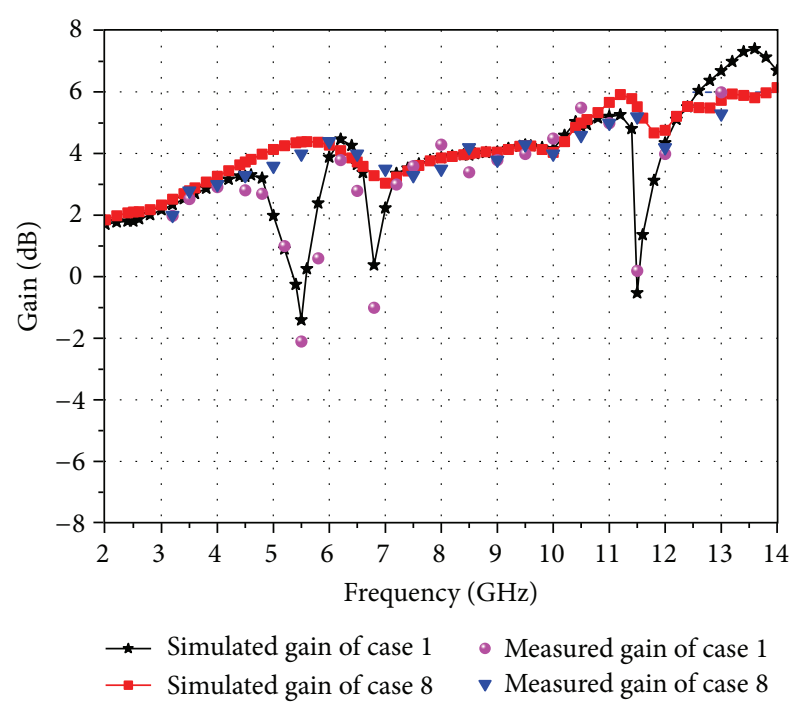

FIgURE 17: Gains of fabricated CRA_C in case 1 and case 8.

China (no. 6131380101). This paper is also supported by the National Nature Science Fund of China (no. 60902014), Nature Science Fund of Heilongjiang (QC2009C66), and the Fundamental Research Funds for the Central Universities (HEUCF1208). The authors are also thankful to Hebei VSTE Science and Technology Co. Ltd. for providing the measurement facility.

\section{References}

[1] Federal communications commission, First report and order, Revision of Part 15 of commission's rule regarding UWB transmission system FCC 02-48, Washington, DC, USA, 2002.

[2] A. Alipour and H. R. Hassani, "A novel omni-directional UWB monopole antenna," IEEE Transactions on Antennas and Propagation, vol. 56, no. 12, pp. 3854-3857, 2008.

[3] M. Kazerooni, A. Cheldavi, and M. Kamarei, "Analysis, modeling, and design of cascaded defected microstrip structure for planar circuits," International Journal of RF and Microwave Computer-Aided Engineering, vol. 20, no. 2, pp. 170-181, 2010.

[4] A. M. Abbosh, "Design of a CPW-Fed band-notched UWB antenna using a feeder-embedded slotline resonator," International Journal of Antennas and Propagation, vol. 2008, Article ID 564317, 5 pages, 2008.

[5] Y.-S. Li, X.-D. Yang, Q. Yang, and C.-Y. Liu, "Compact coplanar waveguide fed ultra wideband antenna with a notch band characteristic," International Journal of Electronics and Communications, vol. 65, no. 11, pp. 961-966, 2011.

[6] Q.-X. Chu and T.-G. Huang, "Compact UWB antenna with sharp band-notched characteristics for lower WLAN band," Electronics Letters, vol. 47, no. 15, pp. 838-839, 2011.

[7] M. Moosazadeh, A. M. Abbosh, and Z. Esmati, "Design of compact planar ultrawideband antenna with dual-notched bands using slotted square patch and pi-shaped conductorbacked plane," IET Microwaves, Antennas and Propagation, vol. 6, no. 3, pp. 290-294, 2012.

[8] Y. Li, X. Yang, C. Liu, and T. Jiang, "Miniaturization cantor set fractal ultrawideband antenna with a notch band characteristic,"
Microwave and Optical Technology Letters, vol. 54, no. 5, pp. 1227-1230, 2012.

[9] A. Djaiz, M. Nedil, M. A. Habib, and T. A. Denidni, "Design of a new UWB-integrated antenna filter with a rejected WLAN band at $5.8 \mathrm{GHz}$," Microwave and Optical Technology Letters, vol. 53, no. 6, pp. 1298-1302, 2011.

[10] Y. Li, W. Li, and Q. Ye, "Compact reconfigurable UWB antenna integrated with SIRs and switches for multi-mode wireless communications," IEICE Electronics Express, vol. 9, no. 7, pp. 629-635, 2012.

[11] R. Eshtiaghi, J. Nourinia, and C. Ghobadi, "Electromagnetically coupled band-notched elliptical monopole antenna for UWB applications," IEEE Transactions on Antennas and Propagation, vol. 58, no. 4, pp. 1397-1402, 2010.

[12] A. Nouri and G. R. Dadashzadeh, "A compact UWB bandnotched printed monopole antenna with defected ground structure," IEEE Antennas and Wireless Propagation Letters, vol. 10, pp. 1178-1181, 2011.

[13] K. S. Ryu and A. A. Kishk, "UWB antenna with single or dual band-notches for lower WLAN band and upper WLAN band," IEEE Transactions on Antennas and Propagation, vol. 57, no. 12, pp. 3942-3950, 2009.

[14] R. Zaker, C. Ghobadi, and J. Nourinia, "Novel modified UWB planar monopole antenna with variable frequency band-notch function," IEEE Antennas and Wireless Propagation Letters, vol. 7, pp. 112-114, 2008.

[15] J. Xu, D. Y. Shen, G. T. Wang, X. H. Zhang, X. P. Zhang, and K. $\mathrm{Wu}$, "A small UWB antenna with dual band-notched characteristics," International Journal of Antennas and Propagation, vol. 2012, Article ID 656858, 7 pages, 2012.

[16] Y. Tawk and C. G. Christodoulou, "A new reconfigurable antenna design for cognitive radio," IEEE Antennas and Wireless Propagation Letters, vol. 8, pp. 1378-1381, 2009.

[17] Y. Tawk, J. Costantine, K. Avery, and C. G. Christodoulou, "Implementation of a cognitive radio front-end using rotatable controlled reconfigurable antennas," IEEE Transactions on Antennas and Propagation, vol. 59, no. 5, pp. 1773-1778, 2011.

[18] Y. Li, W. Li, and R. Mittra, "A cognitive radio antenna integrated with narrow/ultra-wideband antenna and switches," IEICE Electronics Express, vol. 9, no. 15, pp. 1273-1283, 2012.

[19] M. Al-Husseini, A. Ramadan, A. El-Hajj, K. Y. Kabalan, Y. Tawk, and C. G. Christodoulou, "Design based on complementary split-ring resonators of an antenna with controllable band notches for UWB cognitive radio applications," in Proceedings of the IEEE International Symposium on Antennas and Propagation and USNC/URSI National Radio Science Meeting (APSURSI '11), pp. 1120-1122, July 2011.

[20] T. Aboufoul, A. Alomainy, and C. Parini, "Reconfigured and notched tapered slot UWB antenna for cognitive radio applications," International Journal of Antennas and Propagation, vol. 2012, Article ID 160219, 8 pages, 2012.

[21] B. Li, J. Hong, and B. Z. Wang, "Switched band-notched UWB/ dual-band WLAN slot antenna with inverted S-shapedd slots," IEEE Antennas and Wireless Propagation Letters, vol. 11, pp. 572$575,2012$.

[22] M. R. Hamid, P. S. Hall, P. Gardner, and F. Ghanem, "Switched WLAN-wideband tapered slot antenna," Electronics Letters, vol. 46, no. 1, pp. 23-24, 2010.

[23] M. Kazerooni, M. A. Salari, and A. Cheldavi, "A novel method for crosstalk reduction in coupled pair microstrip lines," International Journal of RF and Microwave Computer-Aided Engineering, vol. 22, no. 2, pp. 167-174, 2012. 
[24] S. Zhang, J.-K. Xiao, Z.-H. Wang, and Y. Li, "Novel low pass filters using a defected microstrip structure," Microwave Journal, vol. 49, no. 9, pp. 118-128, 2006.

[25] J.-K. Xiao, W.-J. Zhu, and J. S. Fu, "New bandstop filter using simple defected microstrip structure," Microwave Journal, vol. 54, no. 9, pp. 134-144, 2011.

[26] M. Kazerooni and O. Abbas, "High isolation dual-frequency patch antenna integrated with cascade defected microstrip structure," International Journal of RF and Microwave ComputerAided Engineering, vol. 21, no. 5, pp. 578-583, 2011.

[27] M. Naser-Moghadasi, M. Alamolhoda, and B. Rahmati, "Spurious-response suppression in microstrip Parallel-Coupled bandpass filters by using Defected Microstrip Structures," IEICE Electronics Express, vol. 8, no. 2, pp. 70-75, 2011.

[28] G. Chaudhary, P. Kim, Y. Jeong, J. Lim, and J. Lee, "Analysis and circuit modeling method for defected microstrip structure in planar transmission lines," in Proceedings of the Asia-Pacific Microwave Conference (APMC '11), pp. 999-1002, December 2011.

[29] D. La, Y. Lu, and S. Sun, "Novel bandstop filter using dualU shape defected microstrip structure," in Proceedings of the International Symposium on Signals, Systems and Electronics (ISSSE '10), pp. 400-402, September 2010.

[30] B. Lembrikov, Novel Applications of the UWB Technologies, ch 11, Intech, 2011. 

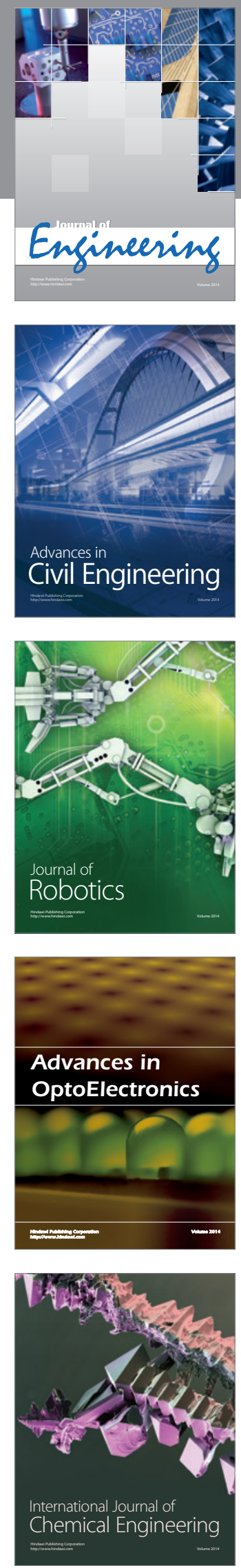

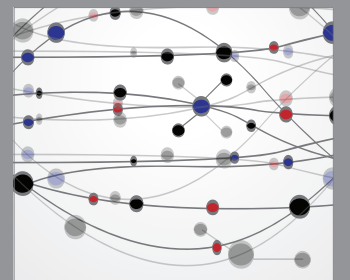

The Scientific World Journal
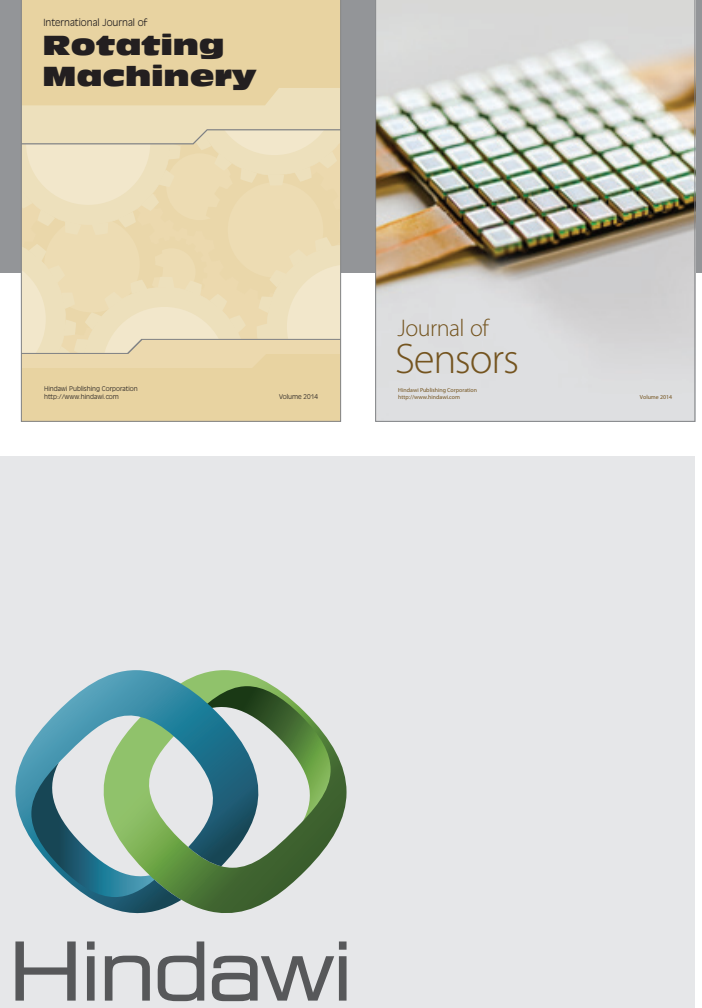

Submit your manuscripts at http://www.hindawi.com
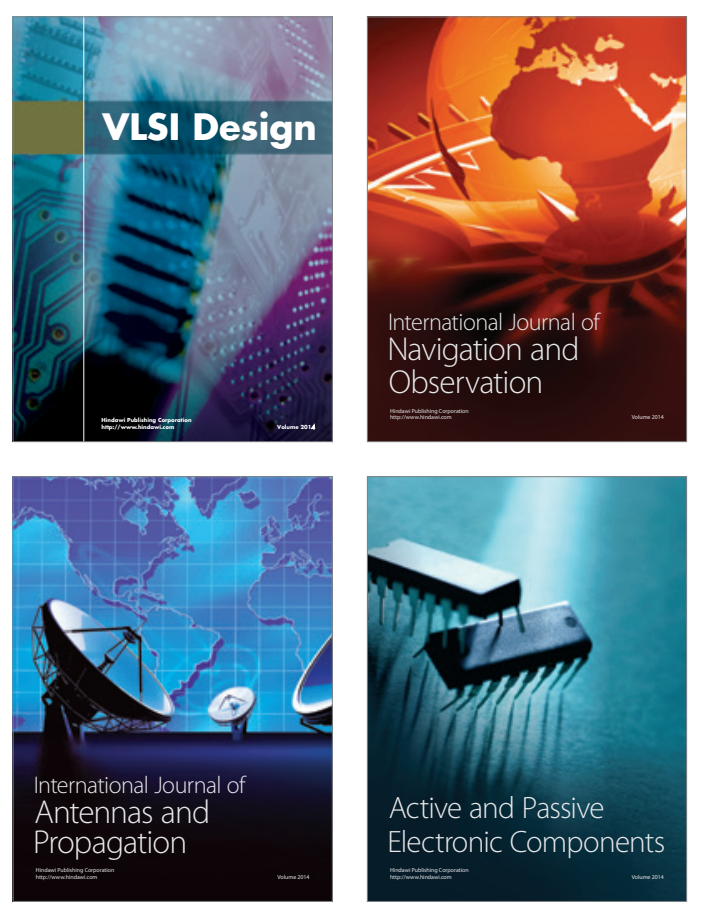
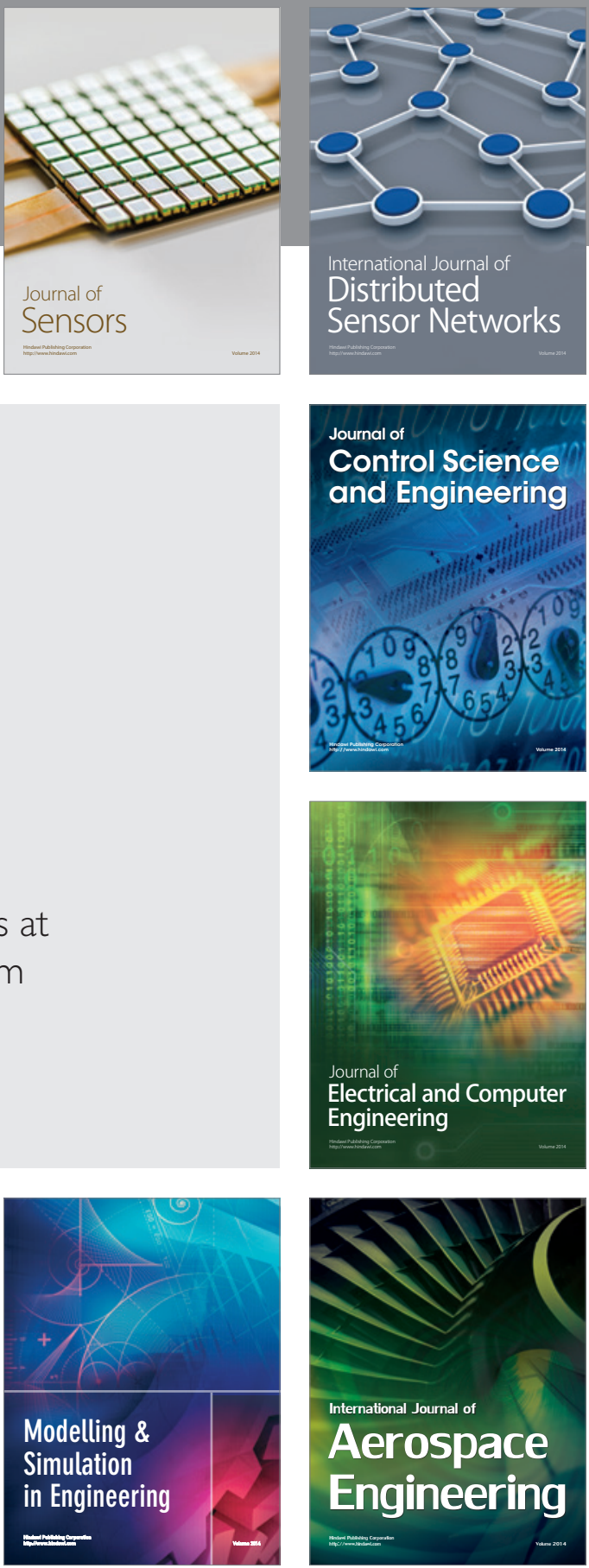

Journal of

Control Science

and Engineering
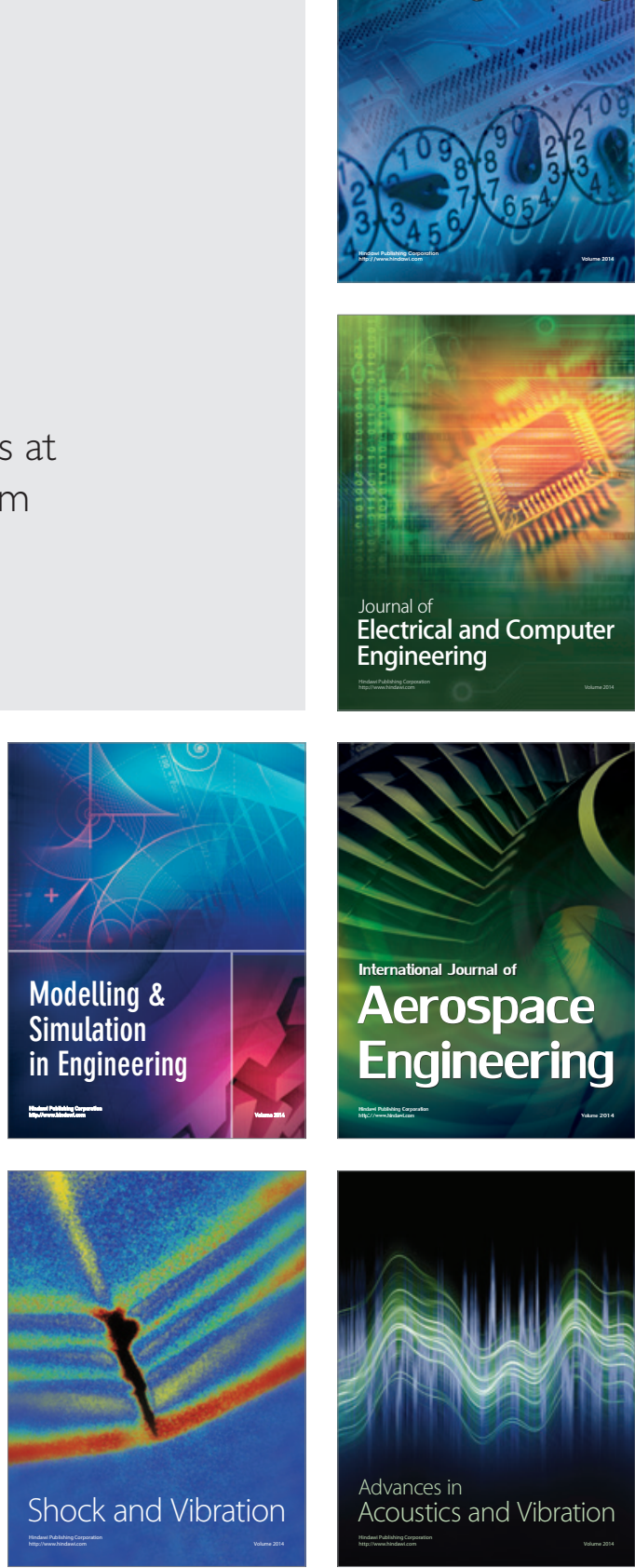